\title{
A Framework for Geometric Quantification and Forecasting of Cost Uncertainty for Aerospace Innovations
}

\author{
Oliver Schwabe ${ }^{\mathrm{a}}$, Essam Shehab ${ }^{\mathrm{a}^{*}}$ and John Erkoyuncu ${ }^{\mathrm{a}}$ \\ ${ }^{\text {a }}$ Cranfield University, Building 50, Cranfield, Bedford MK43 0AL, U.K. \\ * Corresponding author. Tel.: +44 (0) 1234750111 Ext 5241. E-mail address: \\ e.shehab@cranfield.ac.uk
}

\begin{abstract}
Quantification and forecasting of cost uncertainty for aerospace innovations is challenged by conditions of small data which arises out of having few measurement points, little prior experience, unknown history, low data quality, and conditions of deep uncertainty. Literature research suggests that no frameworks exist which specifically address cost estimation under such conditions. In order to provide contemporary cost estimating techniques with an innovative perspective for addressing such challenges a framework based on the principles of spatial geometry is described. The framework consists of a method for visualising cost uncertainty and a dependency model for quantifying and forecasting cost uncertainty. Cost uncertainty is declared to represent manifested and unintended future cost variance with a probability of $100 \%$ and an unknown quantity and innovative starting conditions considered to exist when no verified and accurate cost model is available. The shape of data is used as an organising principle and the attribute of geometrical symmetry of cost variance point clouds used for the quantification of cost uncertainty. The results of the investigation suggest that the uncertainty of a cost estimate at any future point in time may be determined by the geometric symmetry of the cost variance data in its point cloud form at the time of estimation. Recommendations for future research include using the framework to determine the "most likely values" of estimates in Monte Carlo simulations and generalising the dependency model introduced. Future work is also recommended to reduce the framework limitations noted.
\end{abstract}

Keywords: Cost Estimate; Geometry; Symmetry; Topology; Uncertainty 


\section{Introduction}

Increasing technology innovation, competition and regulation are raising the pressure on aerospace organisations to innovate their portfolios in an accelerated manner. These conditions are driving the growth of complexity and financial uncertainty in respect to the whole product life cycle cost. This then leads to innovation hesitance which slows the discovery and deployment of the innovative aerospace solutions required for the society of today and tomorrow. "Innovative" is hereby understood as a condition of products or services where no verified and accurate cost model exist.

One significant aspect of innovation hesitance is related to the challenges of forecasting the cost variance propagation of the technical baseline estimate across the whole product life cycle. Respecting that different types of uncertainty exist and require differentiation $[1,2,2,3,4,5]$ the investigation defines cost uncertainty as manifested and unintended future cost variance with a probability of $100 \%$ and an unknown quantity. This allows for a clear differentiation from the concept of risk where the probability of an unintended event is $<100 \%$ [2] and an estimate of probable impact exists. While the management of uncertainty is subject to various essentially similar industry standards $[6,7,8,9,10,11]$ these generally apply regression based estimation approaches to products which do not address conditions of small data. Conditions of small data arise when few measurement points, little prior experience, no known history low quality data and deep uncertainty are present $[12,13,14,15,16]$. Two fundamental forecasting approaches exist in forward and inverse uncertainty propagation. Forward uncertainty propagation depends on the existence of propagation rules derived through regression approaches. Inverse propagation (or hybrid approaches) cannot be considered since these serve a monitoring purpose. Indeed, if the amount of regressible data available for cost estimation does not admit the use of techniques relying on the Central Limit Theorem then no alternatives appear available [17, 18, 19, 20].

In light of lacking alternatives the opportunities of spatial geometry to address the small data challenge are investigated. As illustrated in Figure 1 standard regression techniques find their applicability when analysing amounts of data commonly found in practice yet become less and less effective as this 
amount moves to big data. In big data we then see applications of geometrical approaches growing. A good example of this is the large volumes of data encountered in engineering simulations. In a similar manner it is suggested that spatial geometry can be applied in the analysis of small data.

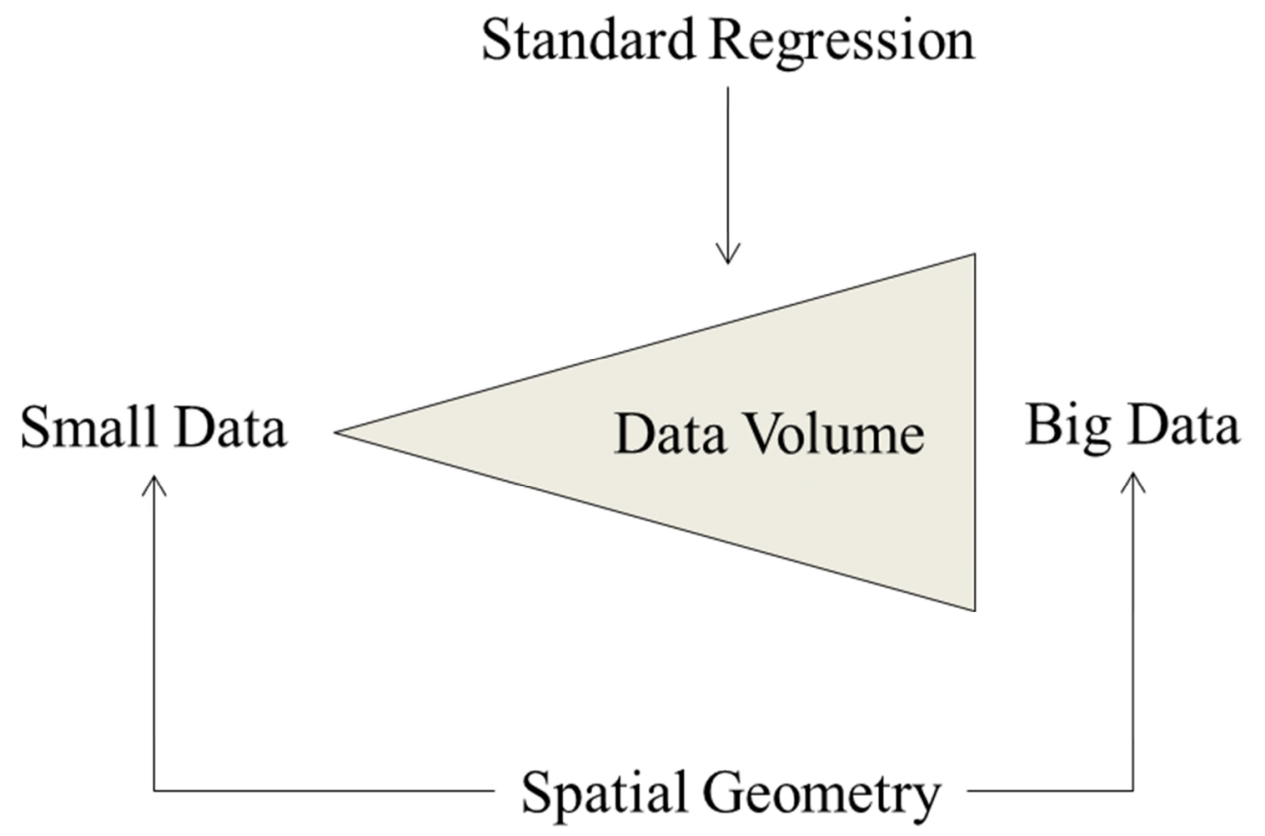

Figure 1: Application areas of spatial geometry for data analysis

The framework contributes to knowledge by providing an alternative to Central Limit Theorem techniques for quantifying cost uncertainty propagation for small data through a repeatable process based on the principles of spatial geometry.

The potential benefit to industry is the ability to forecast the propagation of cost variance based upon small data. This is accomplished without dependency on expert opinion, analogies or application of standard regression approaches that rely on the Central Limit Theorem. This stands in marked contrast to current practice where the cost estimate uncertainty is estimated without reference to a relevant time-window or determination of a decay rate for accuracy.

Section 2 introduces the concepts of spatial geometry and the role of symmetry in its description. Section 3 covers the results of the literature review 
and Section 4 describes the data context analysed. Section 5 provides a detailed description of the framework, including the research methodology, the principle activities related to visualisation, quantification and validation. Section 6 applies the framework to case study data for correlation purposes. Section 7 explores the interdependency of the cost variance dimensions of the case study data. Section 8 validates the results of the investigation including a results comparison, expert opinion and the contribution to knowledge and potential benefits to industry. Section 9 provides a conclusion and recommendations for future work. The theoretical foundations are explored primarily in Section 2 and 3 while the applied perspective is shared in Sections 4, 5, 6 and 7. Sections 8 and 9 are primarily concerned with a discussion of the research results and potentially valuable directions of future research.

\section{Spatial geometry and the role of symmetry}

When faced by small data the estimator is essentially given no or little information at $\mathrm{t}=0$ regarding the (estimated) variance for at least three cost variance dimensions at time $=0$ (i.e. due to changes in engineering requirements, cost estimation principles or schedule) and needs to forecast the cost variance at time $=1$ to $n$. For purposes of the study the estimation of uncertainty from the perspective of spatial geometry with less than three cost dimensions is declared to be feasible only with sufficient prior information which admits the use of regression techniques based on the Central Limit Theorem. Mathematically two fundamentally different approaches exist for the estimator; the arithmetic and the geometric. The validity of this alternative is seen supported by one of the founding fathers of modern statistics, Karl Pearson, who states "Most statistical conclusions which can be obtained by arithmetic, can also be achieved by geometry, and many conclusions can be formed which it would be difficult to reach except by geometry." [21]. The arithmetic perspective focuses on the interdependencies of individual data points themselves (as seen for example in the cost estimating relationship models used in parametric estimation techniques) while the perspective of spatial geometry describe the behaviour of the space created by connecting peripheral data points as illustrated by Figure 2. 


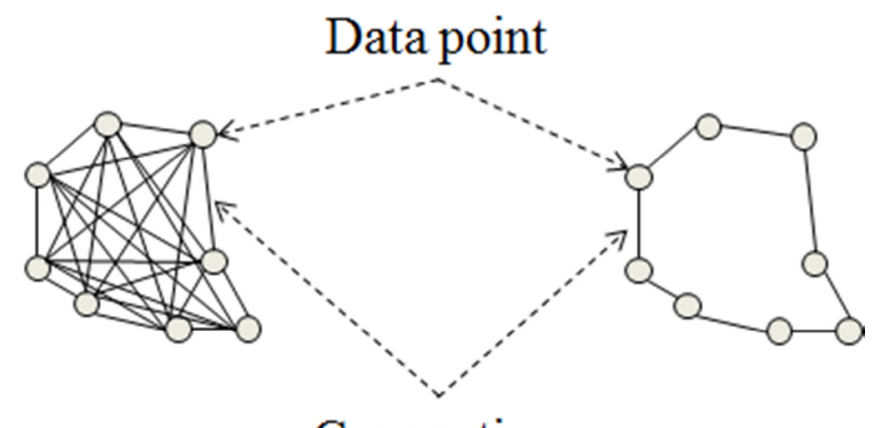

Connection

Arithmetic perspective Geometric perspective

Figure 2: Comparison of arithmetic and geometric perspectives

In order to investigate the geometric perspective the study assumes that the space enclosed by the connections (perimeter) represents a probability space and that cost variance over time can be understood as the propagation of such spaces $[22,23,24,25]$. These spaces can then be described by their geometrical properties [26]. Furthermore advanced cost estimation techniques used by organisations such as the NASA come to the conclusion that evaluating shape "... is typically much more computationally efficient than evaluating a high fidelity physics model of the system. So, replacing a high fidelity model in an analysis by a response surface approximation can rapidly produce an approximate answer to the analysis" [27]. Figure 3 illustrates an exemplary shape created from the geometric perspective.

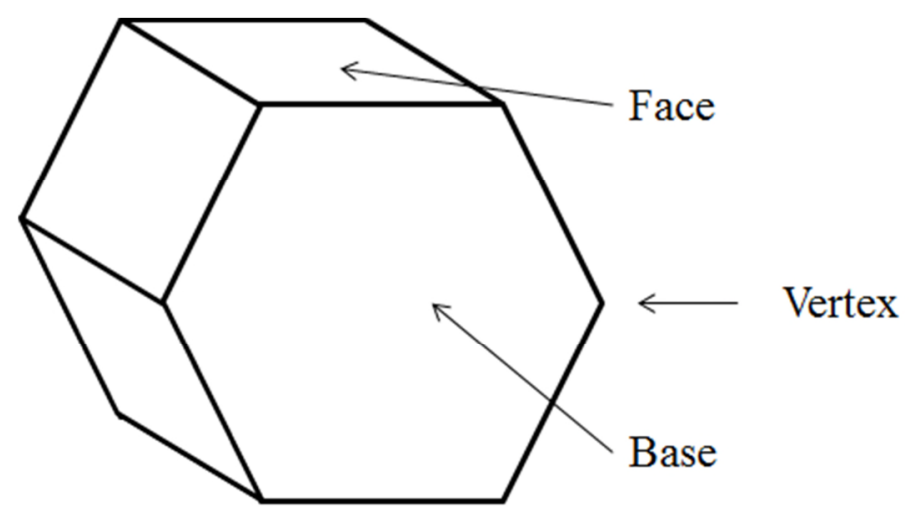

Figure 3: Exemplary shape 
Fundamental geometrical attributes of a shape include metrics such as the number of faces, the number of vertices, area, perimeter, volume and symmetry. Advanced geometrical attributes can be seen in those invariant topological characteristics as measured by metrics such as Euler characteristics, Betti numbers, and bar codes [28]. Advanced attributes were not considered at this stage of the investigation due to the assumption that relevant patterns, if significant enough for cost estimating practice and in consideration of the dynamics and fidelity of cost estimates in general, would be visible at higher levels of abstraction as are represented by linear regressions of fundamental geometric attribute values.

The authors suggest that the fundamental geometrical attribute of symmetry might be the most suitable for describing the propagation behaviour of small data. The attribute of symmetry describes self-similarity of objects under transformations and can be interpreted as information redundancy. The more symmetrical an object, therefore the shape of a cloud of data points enveloped by a response surface, the less information is required to describe it. At the same time if the symmetry is known, then very few data points are required to determine other attributes. Symmetry is hence an important element in gaining a high level understanding of geometry and correspondingly to the dynamics of the context giving rise to it. Important to note is that while a conceptual correlation between symmetry and information entropy can be argued [29] the applicability of such is not subject to the investigation at this stage. If the space created by the cost variance can be determined to have symmetry then an argument might be made for describing its future development in a manner that does not rely on standard statistical regression techniques which depend upon the admissibility of Central Limit Theorem paradigms . The fundamental types of geometrical symmetry are reflection, rotation, scalar, translation and helical as illustrated by Figure 4. 

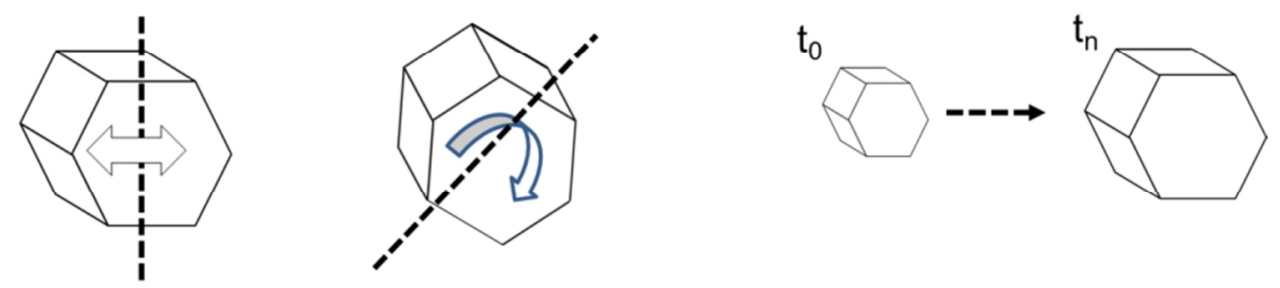

4. Translation

5. Helical
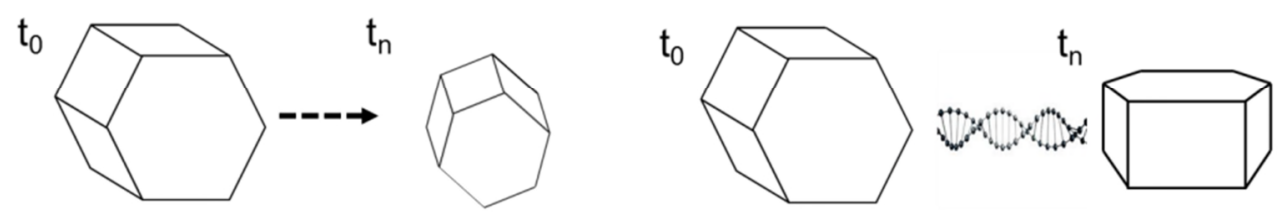

Figure 4: Fundamental types of geometrical symmetry (based on [20])

For purposes of initial investigation a highly simplified interpretation of symmetry is taken by assuming that the closer the area of the base of the shape generated by the data is to the maximum area of the base of the reference shape then the higher the symmetry. The maximum base area for polytopes is given when all side faces are of equal length. Furthermore the concept of the reference shape is approximated for purposes of the investigation to a regular polytope with the number of dimensions defined by the number of data variance dimensions assessed. Specifically, for purposes of the investigation the default reference shape is declared to be a prismatic uniform polyhedron with two identical base polygonal faces where the number of side faces is equal to the number of data dimensions. The difference between the maximum symmetry and area of a reference shape, and the lower symmetry and area of an actual data set are exemplified in Figure 5 using a simplified spider chart representation whereby the scalar values and labels are exemplary only. The reference area at the time of the estimate is given by the blue / light shaded area of Figure 5. The actual area at the time of estimation is given by the red / dark shaded area of Figure 5. The cost variance dimensions used are drawn from the case study context. The range of scalar values is a percentual one for exemplary purposes only. 


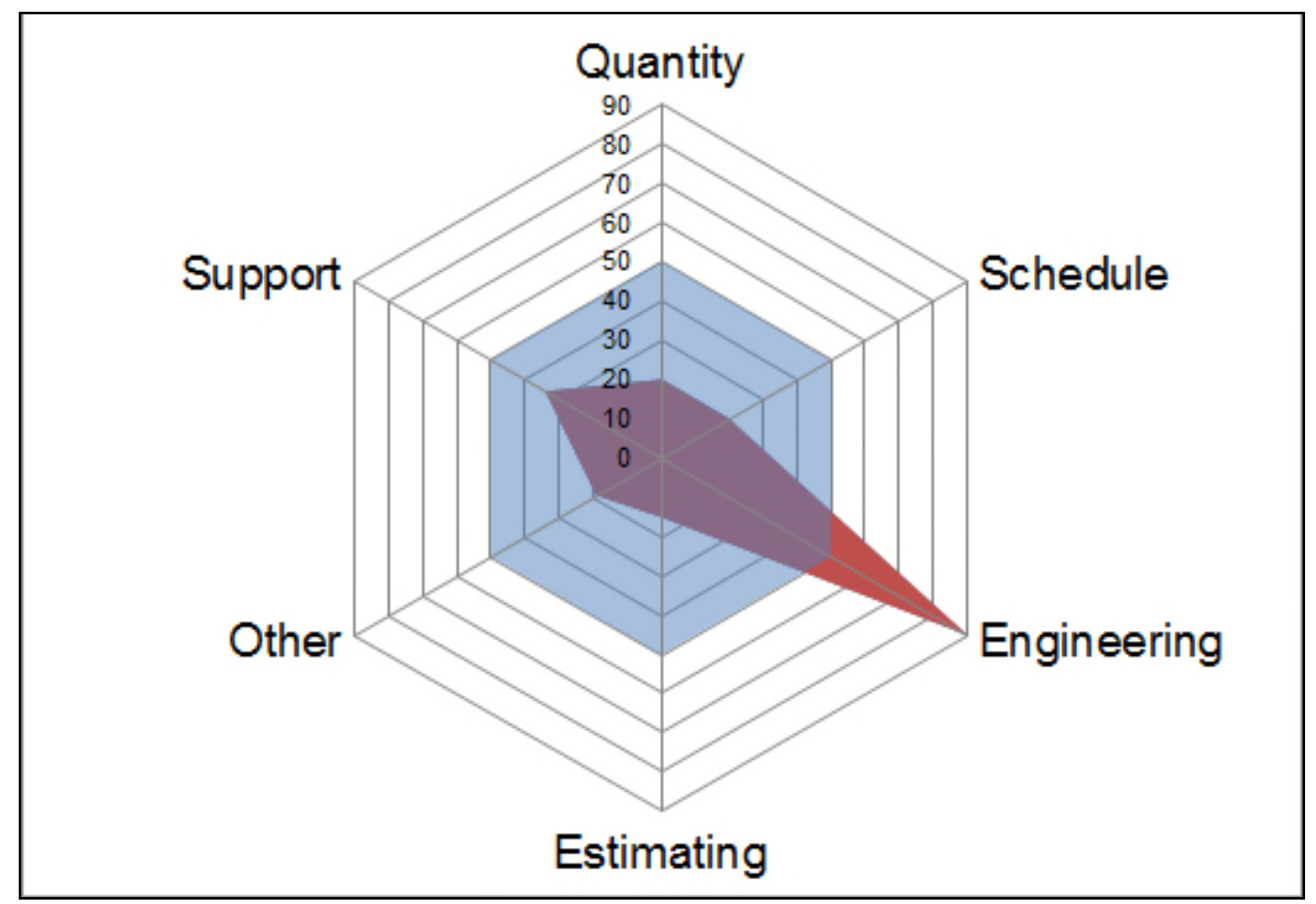

Figure 5: Exemplary comparison of actual and reference areas for exemplary cost variance data for multiple dimensions at a single point in time

\section{Literature review}

The literature review focused on identifying contributions dealing with the use of spatial geometry in cost uncertainty quantification. A search on keywords revealed no direct contributions. Uncertainty appears to be addressed primarily in relation to engineering geometry changes for cost optimization and the geometrical evaluation of cost variance data when this is represented using default Central Limit Theorem based probability density functions such as normal, logarithmic or Weibull distributions. A further emphasis discovered was in the exploration of scientific measurement uncertainty. While spatial geometry is commonly used in the engineering, mathematics, natural sciences, big data and meteorology domains, its application to cost estimation appears to be awaiting further investigation [16].

While a plethora of literature also exists discussing the inadequacy of stateof-practice cost estimation techniques for evaluating large data sets [30] the inadequacies of such techniques for evaluating small data do not find attention. Overall the deduction of patterns in big data sets appears of greater interest to industry and research than the deduction of such from small data 
sets. Of note in this respect was that the application of spatial geometry and spatial statistics for data analysis appears to have significant insensitivity to sampling errors which can be presumed to increase the less data points are available. Bubenik and Kim [31] suggest that, based on a random sampling from an unknown probability density distribution, the deciphering of topological attributes from small data is possible to recover key attributes of more general spatial geometry. It is these attributes which can then be propagated on the basis of the persistent homological attributes, whereby this sequence of complexes must be interpreted through a filtration process that enables the use of simplex geometries [32].

The lack of research regarding the application of spatial geometry for cost estimation approaches is surmised to be due particularly to the (historical) predominance of arithmetic methods in literature and practice, coupled with the wide-spread use of arithmetic tools for forecasting, i.e. MS ${ }^{\circledR}$ Excel or expert estimation software which do not explicitly offer geometric analysis functionalities $[33,34]$. In the face of lacking guidance for estimating without arithmetic techniques, i.e. where the Central Limit Theorem does not apply, estimators will thus, as if clutching at straws, revert to approaches that are commonly used and accept their limitations $[35,36,37]$ versus exploring techniques that may not be as wide-spread but are more suited for the challenge faced as discussed for example by Wheeler [38], Xu et al [39] and Smart [40].

Given that little has been written previously on this subject, the researchers define a series of initial axioms which frame the shape of cost variance data as an attribute of the whole product life cycle and declare that as an open complex system. This system is understood to manifest itself through structural patterns and these patterns can be exposed through changes in shape. The axioms are highlighted as follows:

- Axiom \#1: A system exists in the space defined by the dimensions it is measured by.

- Axiom \#2: The whole product life cycle represents an open complex system.

- Axiom \#3: A system has an infinite number of dimensions. 
- Axiom \#4: The geometry best describing the natural state of a system is a sphere.

- Axiom \#5: The geometrical attribute best describing a sphere is symmetry.

- Axiom \#6: Symmetry is a descriptive attribute of whole product life cycle dynamics.

The research gap can hence be summarised as the lack of a cost uncertainty quantification framework which provides a viable alternative to approaches based on the Central Limit Theorem under conditions of small data. In parallel a relevant research gap arises in respect to the availability of pragmatic techniques for working with multiple data centre frequency distributions and outliers. The two primary challenges related to closing the research gap are the length of the time window between estimation and verification, and the transition between stage gates which often involves a change of cost relevant data, scope, methods, techniques, etc.

\section{Data context}

In order to develop the framework the United States Department of Defense "Selected Acquisition Reports" (SAR) summary tables [41] were used. These reports summarize the latest estimates of cost and schedule on major defence acquisition program cost, schedule, and performance changes for calendar year reporting periods submitted to the United States Congress. Furthermore the total program cost estimates provided in the SARs include research and development, procurement, military construction, and acquisition-related operations and maintenance. Case study data represents an amalgamation of data across various phases of the whole product life cycle for many differing products with aero (space), land and sea mission paths which share the attributes of innovativeness and a degree of cost variance sufficient to trigger increased monitoring by stakeholders.

In the SAR reports the focus was placed on the tables representing base year cost variance and "to date" change figures from the base year were used. Decimals were rounded to full numbers, and absolute figures were used (therefore disregarding whether the variance was positive or negative). Annual SAR summary tables were available for the time period 1970 to 2013. In this 
time period the cost variance factors reported on varied to a degree as highlighted by Table 1.

Table 1: Cost variance factor periods.

Period $\quad$ Reported cost variance factors

1970 Economic, Schedule, Engineering, Estimating, Other, Support, Unpredictable

1971-1974 Economic, Quantity, Schedule, Engineering, Estimating, Other, Support, Unpredictable, Contractor cost overrun, Contract performance incentive

1975-1978 Economic, Quantity, Schedule, Engineering, Estimating, Other, Support, Program change related escalation, Contractor cost overrun

1979-1985 Economic, Quantity, Schedule, Engineering, Estimating, Other, Support, Program change related escalation

1986-2013 Quantity, Schedule, Engineering, Estimating, Other, Support

Important to note is that due to the differing number of variance categories assessed each period is assumed to represent fundamentally different topologies. Breaks in their continuity are assumed to prevent coherent analysis across them. From an arithmetic perspective however these boundaries are often not considered [42] which limits later comparability.

The initial definition of data boundaries was performed in order to create a continuous set of data with the same financial baseline. This consisted of 1410 reports representing 49 unique programs in the time period 1986-2013. Initial investigation of sample size requirements determined that since the data set being examined could not be verified to follow the Law of Large Numbers on any attribute, a corresponding determination of a minimum sample size attribute was not admissible. The sample size was thus declared to be sufficient for the investigation. The cost variance factors used by the SAR in the period 1986-2013 can be interpreted as follows [42]: 
- Quantity: A cost variance that is due to a change in the number of units of an end item of equipment.

- Schedule: Costs resulting from change in procurement or delivery schedule, completion date, or intermediate milestone for development or production.

- Engineering: Cost increases or decreases that are due to an alteration in the physical or functional characteristics of a system or item delivered.

- Estimating : Changes due solely to the correction of previous estimating errors or to refinements of a current estimate.

- Other: Cost variances that are due to unforeseeable events not covered in any other category (e.g. natural disaster or strike).

- Support: Any change in cost, regardless of reason, associated with support equipment for the major hardware item (defined as any work breakdown structure element not included in flyaway, rollaway, or sail-away costs).

The source data used for the investigation is summarised at an aggregated level (therefore the total cost variance against baseline estimates for all projects reported on in the relevant annual SAR) in 
Table 2. Values in cursive text represent negative cost variance, whereby this is treated as absolute figures for purposes of the investigation. The source data was chosen due its public availability (which allows for independent verification of study results) and due to it being the data set closest to the aim of the study. 
Table 2: Source data overview

\begin{tabular}{|c|c|c|c|c|c|c|}
\hline $\begin{array}{l}\text { Reporting } \\
\text { Period (ending } \\
\text { December) }\end{array}$ & $\begin{array}{l}\text { Quantity } \\
\text { (US\$ mil.) }\end{array}$ & $\begin{array}{l}\text { Schedule } \\
\text { (US\$ mil.) }\end{array}$ & $\begin{array}{c}\text { Engineering } \\
\text { (US\$ mil.) }\end{array}$ & $\begin{array}{l}\text { Estimating } \\
\text { (US\$ mil.) }\end{array}$ & $\begin{array}{c}\text { Other } \\
\text { (US\$ mil.) }\end{array}$ & $\begin{array}{c}\text { Support } \\
\text { (US\$ mil.) }\end{array}$ \\
\hline 1986 & 72810 & 6460 & 15729 & 2493 & 696 & 14545 \\
\hline 1987 & 46441 & 5525 & 14241 & 7473 & 9810 & 2392 \\
\hline 1988 & 78291 & 6436 & 17792 & 1903 & 9463 & 1196 \\
\hline 1989 & 48649 & 5009 & 15839 & 4921 & 8253 & 10297 \\
\hline 1990 & 17036 & 13212 & 16428 & 16122 & 8126 & 13859 \\
\hline 1991 & 25126 & 8797 & 12564 & 22750 & 9554 & 11277 \\
\hline 1992 & 12110 & 11256 & 12516 & 17158 & 797 & 1311 \\
\hline 1993 & 30532 & 14017 & 11930 & 3375 & 250 & 4476 \\
\hline 1994 & 16973 & 11927 & 9156 & 3942 & 176 & 3244 \\
\hline 1995 & 3090 & 11065 & 4873 & 32348 & 229 & 879 \\
\hline 1996 & 9969 & 12613 & 4861 & 33229 & 342 & 2271 \\
\hline 1997 & 30805 & 11931 & 2955 & 33402 & 342 & 6504 \\
\hline 1998 & 28964 & 13072 & 8608 & 43191 & 313 & 6868 \\
\hline 1999 & 28043 & 14499 & 12464 & 54642 & 777 & 6951 \\
\hline 2000 & 31837 & 15381 & 12867 & 58614 & 784 & 7746 \\
\hline 2001 & 22364 & 10965 & 25677 & 94897 & 894 & 7708 \\
\hline 2002 & 12960 & 8117 & 47290 & 102207 & 906 & 6389 \\
\hline 2003 & 9043 & 16928 & 47860 & 116758 & 762 & 10576 \\
\hline 2004 & 23442 & 25146 & 73302 & 111189 & 77 & 12300 \\
\hline 2005 & 840 & 27913 & 94310 & 11890 & 778 & 23941 \\
\hline 2006 & 432 & 31994 & 91098 & 105687 & 937 & 32864 \\
\hline 2007 & 2651 & 32800 & 91989 & 109095 & 2200 & 18991 \\
\hline 2008 & 9090 & 33545 & 92007 & 109472 & 2200 & 17871 \\
\hline 2009 & 13256 & 26907 & 73342 & 138170 & 2613 & 36233 \\
\hline 2010 & 27714 & 21833 & 74409 & 125852 & 1836 & 37892 \\
\hline 2011 & 2902 & 24248 & 67531 & 124486 & 1830 & 21059 \\
\hline 2012 & 33221 & 4743 & 54354 & 40907 & 1839 & 7237 \\
\hline 2013 & 15647 & 6915 & 53882 & 731 & 1782 & 2795 \\
\hline
\end{tabular}

\section{Framework}

The framework was developed based upon observations of the long term cost variance data behaviour in the data context. These observations used multiple covariate regression analyses to identify potential patterns in the relationship between cost variance data and fundamental attributes of spatial geometry of the relevant point cloud. In order to visualise this the framework visualises uncertainty as a n-dimensional shape, quantifies uncertainty using the 
symmetry of the shape, and validates this uncertainty through a process of inverse uncertainty quantification independent of the technical baseline cost estimate and risk contingency.The developed process is illustrated by Figure 6 .

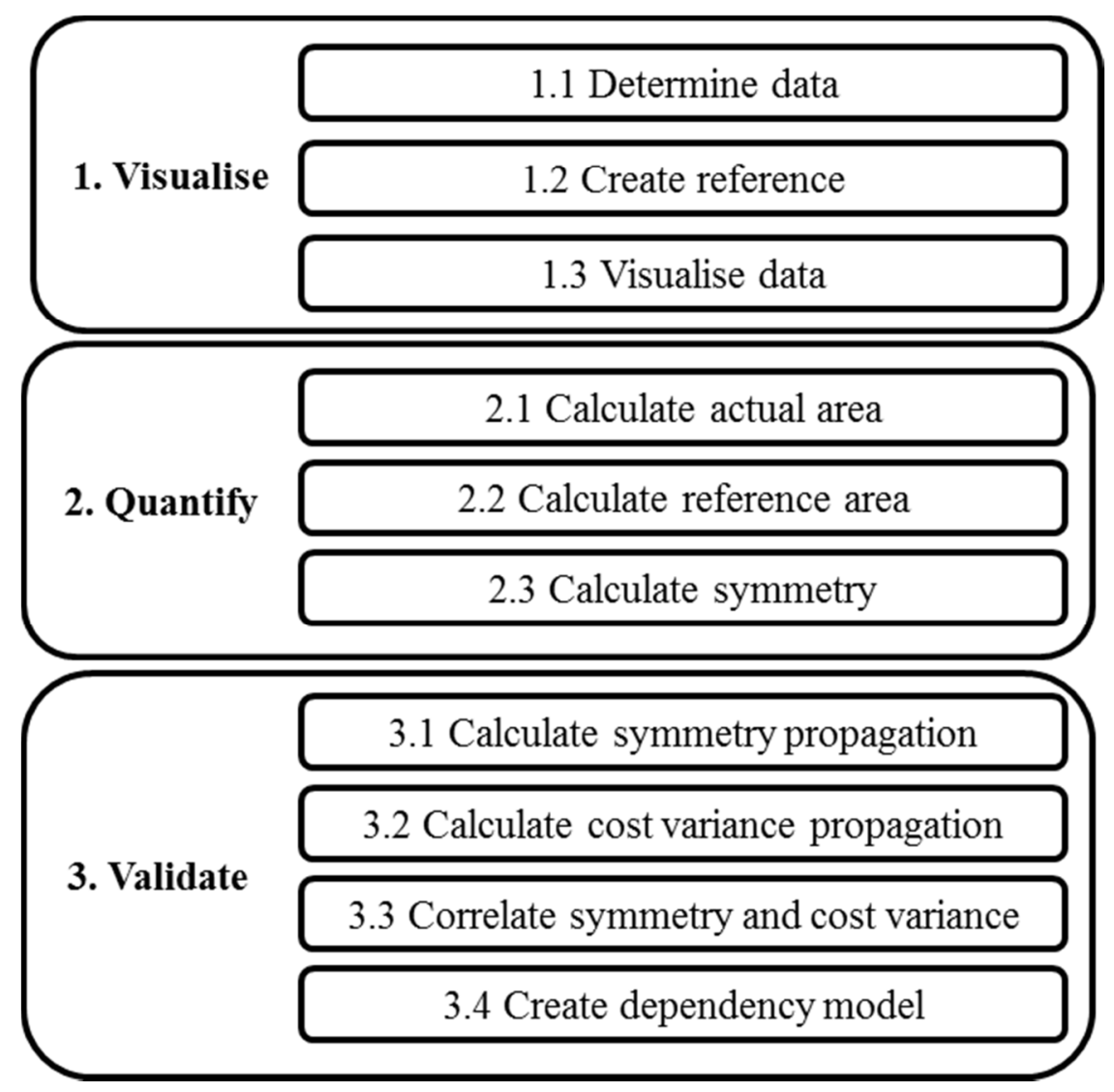

Figure 6: Framework

\subsection{Visualise}

In a first step the absolute cost variance as compared to the base year estimate is determined as illustrated by the scatter-gram in Figure 7. As throughout the investigation a scatter-gram is chosen to visualize two-dimensional data. This allows for a presentation of primary data in a manner which is easily understood. 


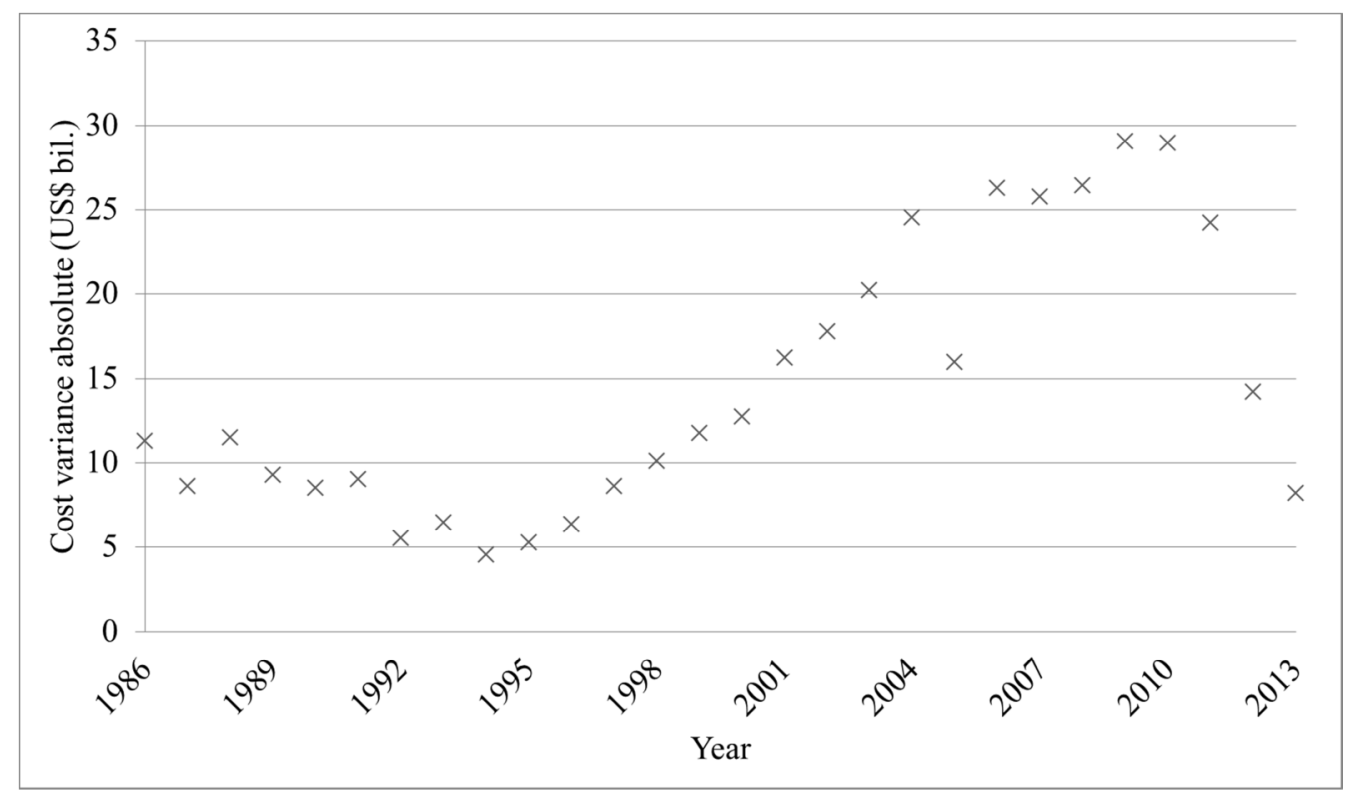

Figure 7: Absolute yearly cost variance 1986-2013

Each data point is then visualised as an n-dimensional geometrical shape using a spider chart representation whereby the dimensions are determined by the number of cost variance dimensions assessed (therefore Quantity, Schedule, Engineering, Estimating, Other and Support [41]) and considered as vertices of the spider chart. The visualisation occurs at minimum for a single time-slice but may extend over any number of time slices depending on the amount of continuous historical data available for at least three dimensions. The number of dimensions determines the geometrical reference shape, i.e. if eight dimensions are assessed then a prismatic uniform octagon would be used for this purpose.

For exemplary purposes specific data is drawn from the aggregated SAR summary tables for 2012. The number and type of cost variance dimensions are identified and the absolute values determined. The result is illustrated in Table 4. 
Table 3: Sample output process step 1

\begin{tabular}{lcc}
\hline \multicolumn{1}{c}{ Dimension } & Value (US\$ mil.) & \% of total \\
\hline & & \\
Quantity & 33221 & $23.35 \%$ \\
Schedule & 4743 & $3.33 \%$ \\
Engineering & 54354 & $38.20 \%$ \\
Estimating & 40907 & $28.75 \%$ \\
Other & 1839 & $1.29 \%$ \\
Support & 7237 & $5.09 \%$ \\
\hline
\end{tabular}


Table 3 shows the only input to the method and may consist of data for only one time period. The $\%$ of total values is calculated based on the sum of the input values. In the absence of data the values can be estimated using analogy or expert opinion. The number of cost variance dimensions assessed is found in the source data and values must be available for each dimension, whereby a value of " 0 " is admissible and all negative values should be converted into positive ones. Data must also share a common financial baseline.

The reference shape needed for organising the data is described by the number and altitude of faces and the number and height of vertices. For a regular reference shape the number of faces equals the number of vertices. The number of cost variance dimensions assessed determines the number of vertices. For the example chosen six cost variance dimensions need to be considered and hence a hexagonal polytope is chosen as a reference shape as illustrated in Figure 8.

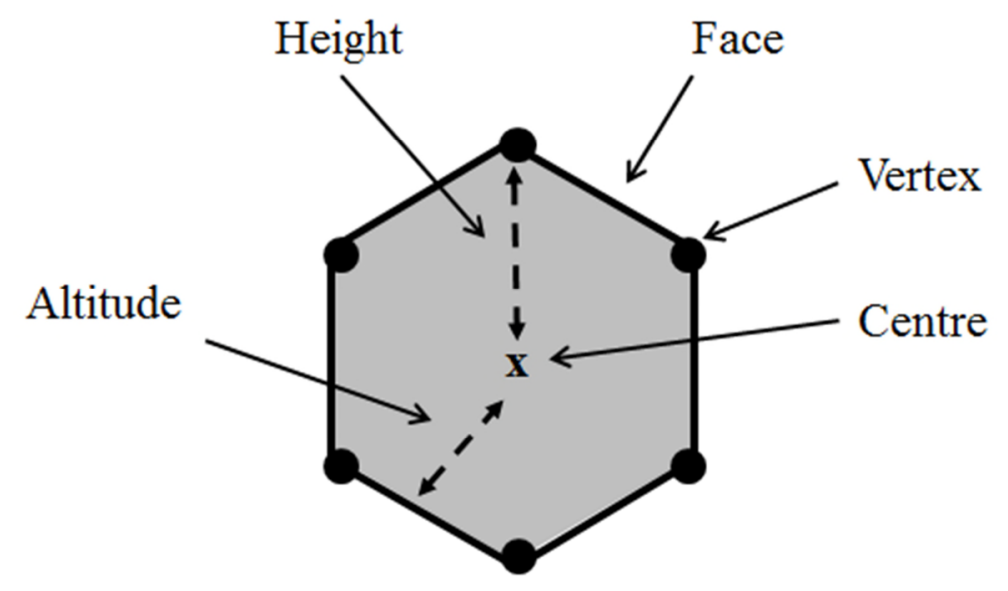

Figure 8: Sample reference shape

If only five dimensions were relevant then a pentagonal polytope would be chosen or a triangular polytope for three dimensions. Less than three dimensions cannot be evaluated with this framework. If seven dimensions were relevant then a heptagonal polytope would be chosen and so on.

The reference shape is then used to create a first geometric visualisation of the data. The input to this activity is the financial figures for each cost variance 
dimension. Each cost variance dimension is represented as a unique line from the centre of the prism to a vertex on the perimeter. The length of each line is deemed to represent the value of the cost variance for that dimension. This transformation results in a visualisation which is commonly termed a spider chart. Figure 9 illustrates the reference shape whereby the value of the dimensions is equal for orientation purposes only. The range of scalar values is in US\$ million.

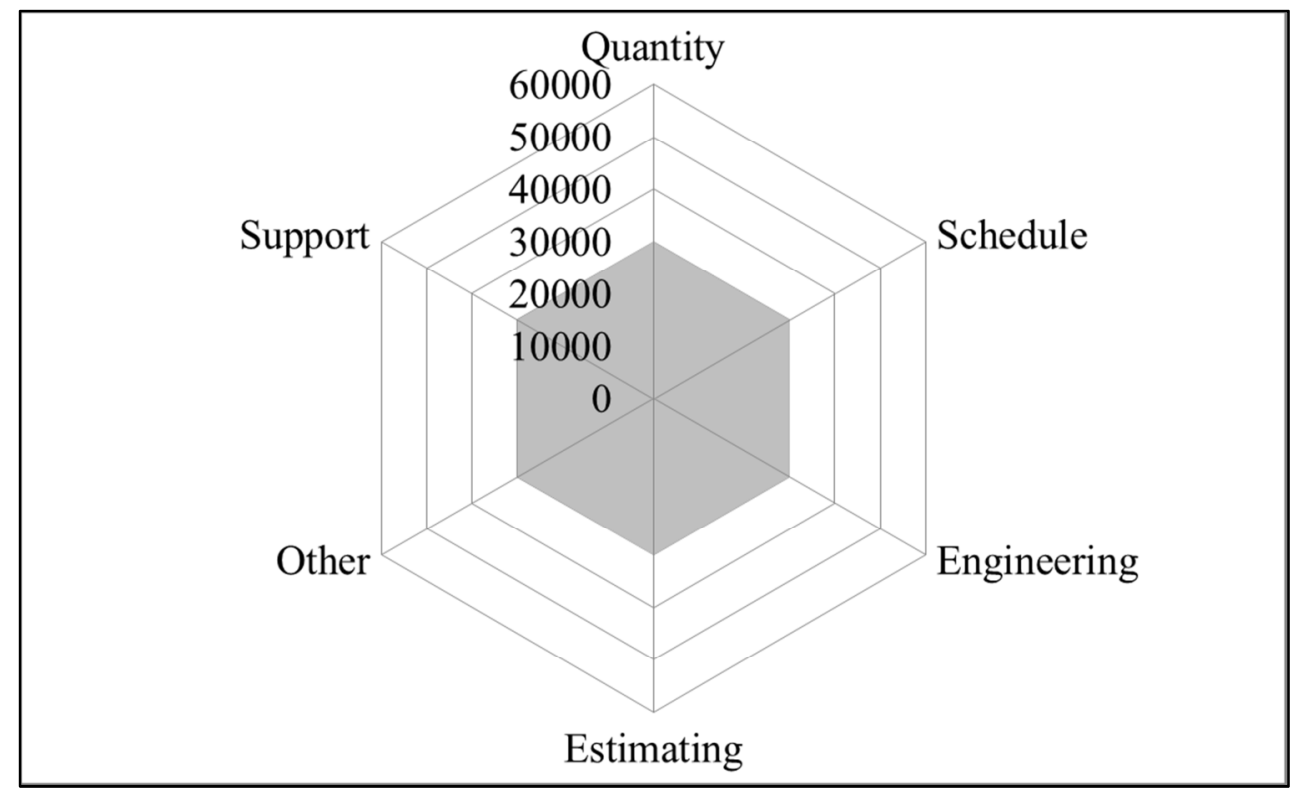

Figure 9: Unpopulated reference shape

The visualisation is then populated with the sample data as illustrated in Figure 10. The range of scalar values is in US\$ million. 


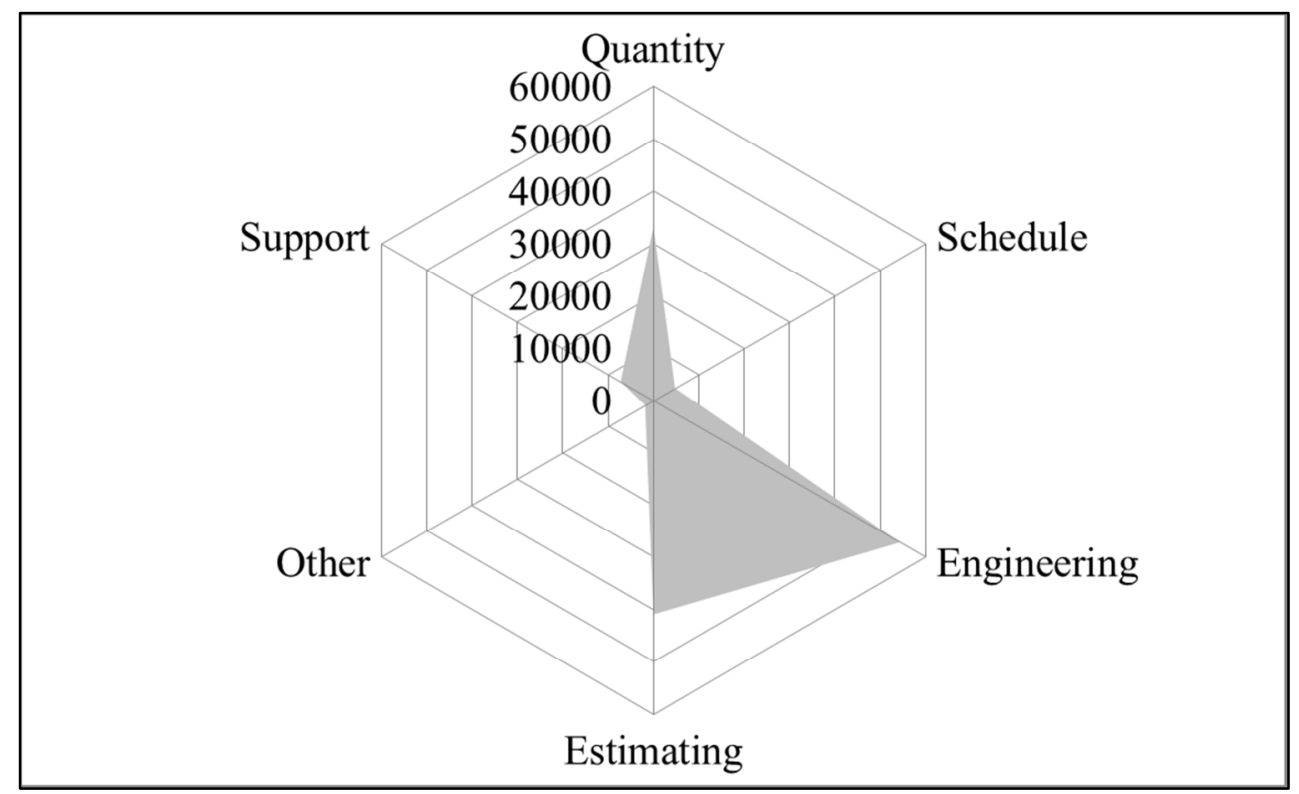

Figure 10: Visualisation of sample case study data

Important to note is that the area of the shapes does not quantify the cost uncertainty. It is only in the following quantification step that the comparative shape of these areas is used to determine the symmetry of the shape as the quantification metric of relevance. This is then correlated with compounded cost variance and this correlation used for forecasting the cost uncertainty ranges.

The framework developed for the investigation thus treats cost variance as the vertices of such simplex geometries propagating over time and proposes to consider the changes in these geometries as manifested uncertainty.

\subsection{Quantify}

In a second step an input output model is used to quantify the uncertainty of the data through the geometrical attribute of symmetry. The symmetry is hereby determined by the relationship between the actual volume of the evaluated slice and the maximum volume possible with the actual perimeter of the created geometry. The maximum volume occurs when all sides of the regular reference shape are of equal length. Since the investigation uses only a single time slice, its volume can be considered to equal the area of its base face (due to height of a single time slice being considered as "1"). The input output model is illustrated in Figure 11. 


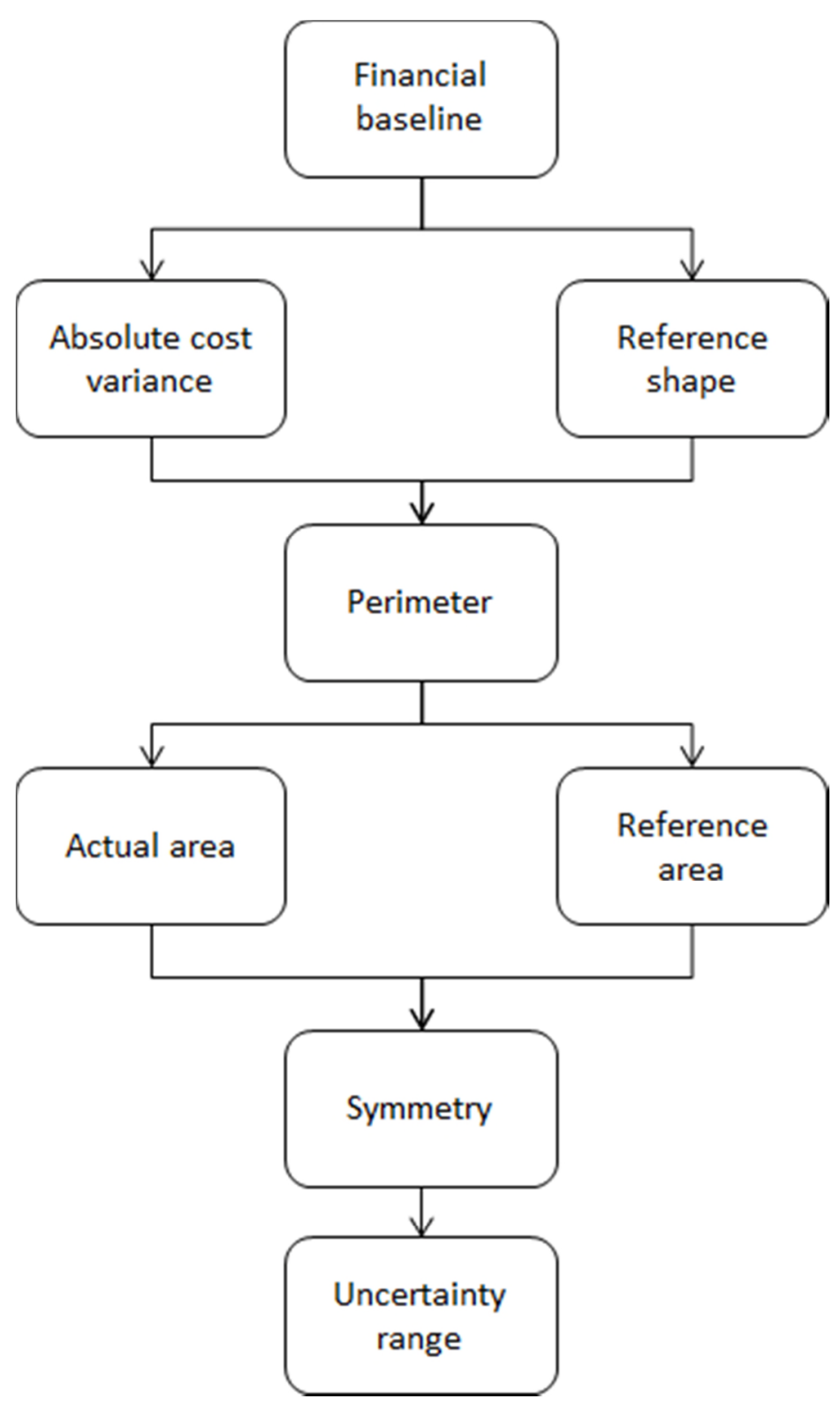

Figure 11: Input output model

The input output model finds its foundation in the financial baseline for the data being evaluated. The financial baseline determines the absolute cost variance and the number of variance dimensions which determine the reference shape. The combination of absolute cost variance with the reference shape allows for the calculation of the shape perimeter and actual area. The reference shape in combination with the actual perimeter then allows for calculation of the reference area. The actual and reference areas allow for the determination of symmetry and based upon this the uncertainty range. 
In order to calculate the area within the perimeter of the populated reference shape the first step is to identify the triangles constituting the shape whereby all triangles share the centre of the shape as their apex as illustrated in Figure 12.

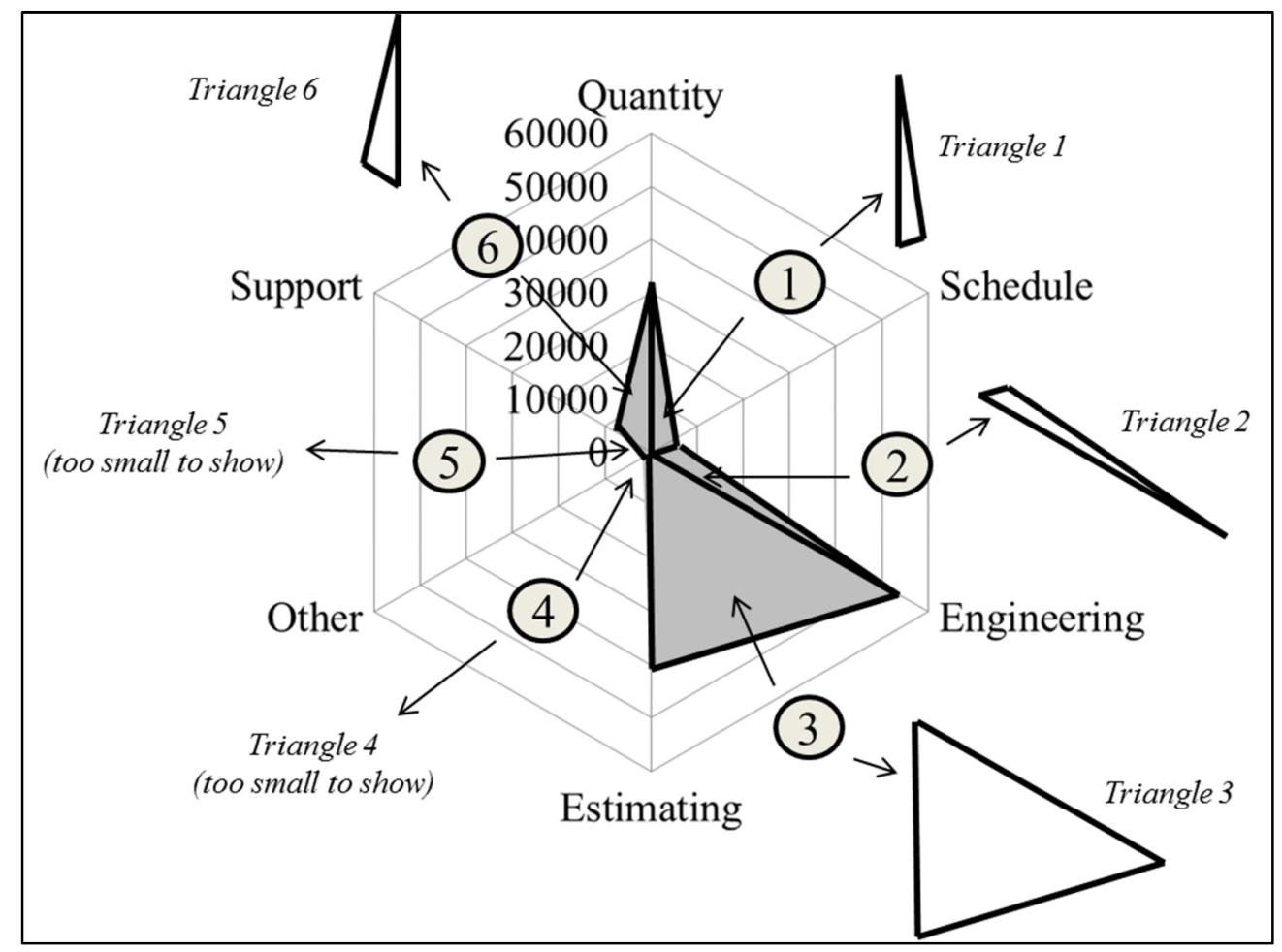

Figure 12: Sample calculation (with exploded triangles)

Triangle 1 describes the area between the centre, the "Quantity" vertex and the "Schedule" vertex. Triangle 2 describes the area between the centre, the "Schedule" vertex and the "Engineering" vertex. Triangle 3 describes the area between the centre, the "Engineering" vertex and the "Estimating" vertex. Triangle 4 describes the area between the centre, the "Engineering" vertex and "Other" vertex. Triangle 5 describes the area between the centre, the "Other" vertex and the "Support" vertex. Triangle 6 describes the area between the centre, the "Support" vertex and the "Quantity" vertex. Triangles 4 and 5 are too small to be seen in Figure 12.

Each triangle is defined by two legs leading from the centre to two vertices. In this case the area of six (isosceles) triangles needs to be calculated. Since the reference shape is regular the central angle of each triangle is identical 
therefore $360^{\circ} / 6=60^{\circ}$. With a known central angle and two known vertex lengths the area for each triangle is now given by Equation 1. The unit of measure is the unit of the vertex value squared (in this case therefore USD\$ million $^{2}$ ). The meaning of the actual area value calculated is found only in the relative value to the reference area value calculated in a later step.

$$
\begin{aligned}
& \text { Example: Area of triangle } 1 \\
& \qquad \begin{array}{l}
=(0.5 *(\text { Height of Vertex } 1) \\
*(\text { Height of Vertex } 2) * \operatorname{SIN}(-60))
\end{array}
\end{aligned}
$$

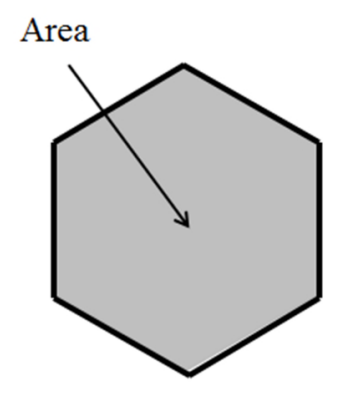

Equation 1: Area of an isosceles triangle

For triangle 1 vertex 1 height is the value of the quantity vector (therefore US\$ 33221 mil.) and vertex 2 height is the value of the schedule vector (therefore US\$ 4743 mil.). These numbers can then be used to calculate the area of triangle 1:

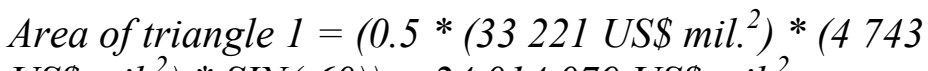
US\$ mil. $\left.\left.{ }^{2}\right) * \operatorname{SIN}(-60)\right)=24014079$ US\$ mil. ${ }^{2}$

After calculating the area for each triangle these areas can be summed up to give the overall area of the populated reference shape. Results using the exemplary data are provided in Table 4.

Table 4: Actual area calculation

\begin{tabular}{cc}
\hline Triangle & $\begin{array}{c}\text { Area } \\
\text { (US\$ million }^{2} \text { ) }\end{array}$ \\
\hline & \\
1 & 24014079 \\
2 & 39290245 \\
3 & 338866971 \\
4 & 11465143 \\
5 & 2028338 \\
6 & 36641342 \\
Sum & 452306118 \\
\hline
\end{tabular}

Important to note is that if dimensions with a value of " 0 " are adjacent the area will be " 0 " for that geometrical segment.

After calculating the area the next required metric is the total perimeter. This is required in order to determine the length of the sides of the regular 
reference shape whose area represents the maximum area that can be enclosed by that perimeter. In order to calculate the perimeter the outer face length of each of the six triangles is calculated and these added. The outer face length of triangle 1 is given by Equation 2 and can be iteratively applied to each of the six triangles. The unit of measure is the same as the unit of measure for the vertex height (therefore US\$ million). The meaning of the perimeter length is found only in being a required input to the area calculation of the reference area.

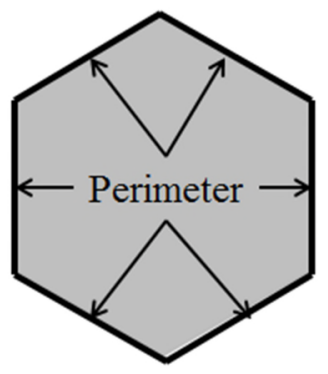

$$
\begin{aligned}
& \text { Outer face length of triangle } 1 \\
& =\sqrt{ }\left(\left(\text { Height of Vertex } 1^{2}\right)\right. \\
& +\left(\text { Height of Vertex } 2^{2}\right)-2 \\
& \text { * (Height of Vertex } 1 * \text { Height of Vertex } 2 \\
& * \operatorname{COS}(60))
\end{aligned}
$$

Equation 2: Perimeter of reference shape

For triangle 1 vertex 1 height is the value of the quantity vector (therefore US\$ $33221 \mathrm{mil}$.) and vertex 2 height is the value of the schedule vector (therefore US\$ 4743 mil.). These numbers can then be used to calculate the outer face length of triangle 1 :

Outer face length of triangle $1=\sqrt{ }\left(\left(\begin{array}{ll}33 & \left.221 \text { US } \$ \text { mil. }^{2}\right) \\ \end{array}\right)+(4743\right.$ US\$ mil. $\left.{ }^{2}\right)-2 *\left(33221\right.$ US\$ mil. $^{2} * 4743$ US\$ mil. ${ }^{2} *$ COS(60)) $=37766$ US\$ mil. ${ }^{2}$

Results for the perimeter calculation using the exemplary data are provided by Table 5 .

Table 5: Perimeter calculation

\begin{tabular}{cc}
\hline Face & $\begin{array}{c}\text { Length } \\
\text { (US\$ million) }\end{array}$ \\
\hline & \\
1 & 37766 \\
2 & 58889 \\
3 & 94144 \\
4 & 42662 \\
5 & 9006
\end{tabular}


Based on the total perimeter the area of the reference shape can be calculated by dividing the total perimeter by the number of dimensions in the base data, therefore six, in order to determine the face length of the reference shape. The area of the reference prism requires the calculation of the altitude edge using Equation 3. The unit of measure is the same as the unit of measure for the vertex height (therefore US\$ million). The meaning of the altitude length is found only in being a required input to the area calculation of the reference area.

$$
\begin{aligned}
& \text { Altitude of reference prism } \\
& \qquad \begin{aligned}
& \sqrt{ }\left(\left(\text { Reference Face Length }{ }^{2}\right)\right) \\
& -\left(\left(\frac{\text { Reference Face Length }}{2}\right)\right. \\
& \left.\left.*\left(\frac{\text { Reference Face Length }}{2}\right)\right)\right) \\
& \text { Equation 3: Altitude calculation }
\end{aligned}
\end{aligned}
$$

For the example data the reference face length is 47107 US\$ mil. These numbers can then be used to calculate the altitude of the reference shape:

Altitude of reference shape $=\sqrt{ }\left(\left(47107\right.\right.$ US\$ mil..$\left.\left.^{2}\right)\right)-((47107$ US\$ mil. $\left.{ }^{2} / 2\right) *\left(47107\right.$ US\$ mil. $\left.^{2} / 2\right)=40796{\text { US\$ } \text { mil. }^{2}}^{2}$ 
The vertex height can then be calculated using Equation 4. The meaning of the vertex height is found only in being a required input to the area calculation of the reference area.

$$
\begin{aligned}
& \text { Vertex height of reference prism } \\
& =\sqrt{ }\left(\left(\text { Altitude of Reference Prism }{ }^{2}\right)\right. \\
& +\left(\text { Face Length of Reference Prism }{ }^{2}\right)
\end{aligned}
$$

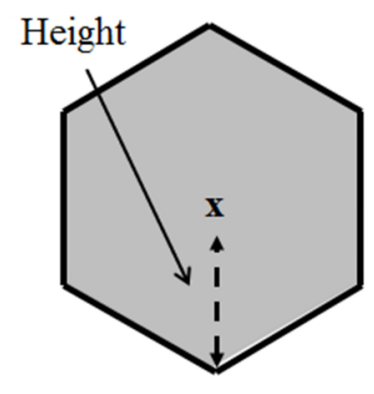

Equation 4: Vertex height calculation

For the example data the altitude of the reference prism is 796 US\$ mil. ${ }^{2}$ and the reference face length is 47107 US\$ mil. ${ }^{2}$. These numbers can then be used to calculate the altitude of the reference shape:

Vertex height of reference prism $=\sqrt{ }\left(\left(\left(796 \text { US } \$ \text { mil. }^{2}\right)^{2}\right)+((47107\right.$ US\$ mil. $\left.\left.{ }^{2}\right)^{2}\right)=47114$ US $\$$ mil. $^{2}$

Results for the reference area calculated with exemplary data are provided in Table 6.

Table 6: Reference shape attributes

\begin{tabular}{cc}
\hline Reference shape attribute & Value \\
\hline Perimeter (Total edge length) & 47106 US\$ million \\
Area & 2029174791 US\$ million ${ }^{2}$ \\
\hline
\end{tabular}

Now that the actual area (based on actual face lengths) and the maximum area (based on equal face lengths) have been calculated, the symmetry of the actual area is determined as indicated by Equation 5. The inputs are the actual area of cost variance divided by the reference area of cost variance. 
Symmetry $=\frac{\text { Actual Area }}{\text { Reference Area }}$

Equation 5: Symmetry calculation

Results for calculating symmetry with the exemplary data are provided in Table 7.

Table 7: Symmetry calculation

\begin{tabular}{lc}
\hline \multicolumn{1}{c}{ Variable } & Value \\
\hline & \\
Actual area & 452306118 US\$ million \\
Reference area & 2029174791 US\$ million \\
Symmetry & $22.29 \%$ \\
\hline
\end{tabular}

Important to note in this respect is that based on the definition of symmetry put forward the higher the symmetry value is the greater the expected uncertainty range will be.

\subsection{Forecast}

The forecast step of the framework concerns the correlation of the quantification results for compounded cost variance propagation with the propagation of the symmetry of the shape over time. Using the quantification technique presented the change in symmetry over time is first determined, then the change in compounded cost variance over time calculated, and finally the two examined for potential correlation.

The absolute yearly cost variance from 1986-2013 is illustrated in Figure 7. The scatter-gram in Figure 13 illustrates the area of the spider chart representing the cost variance between the financial baseline and the actual cost in each year using the steps of the quantification process. 


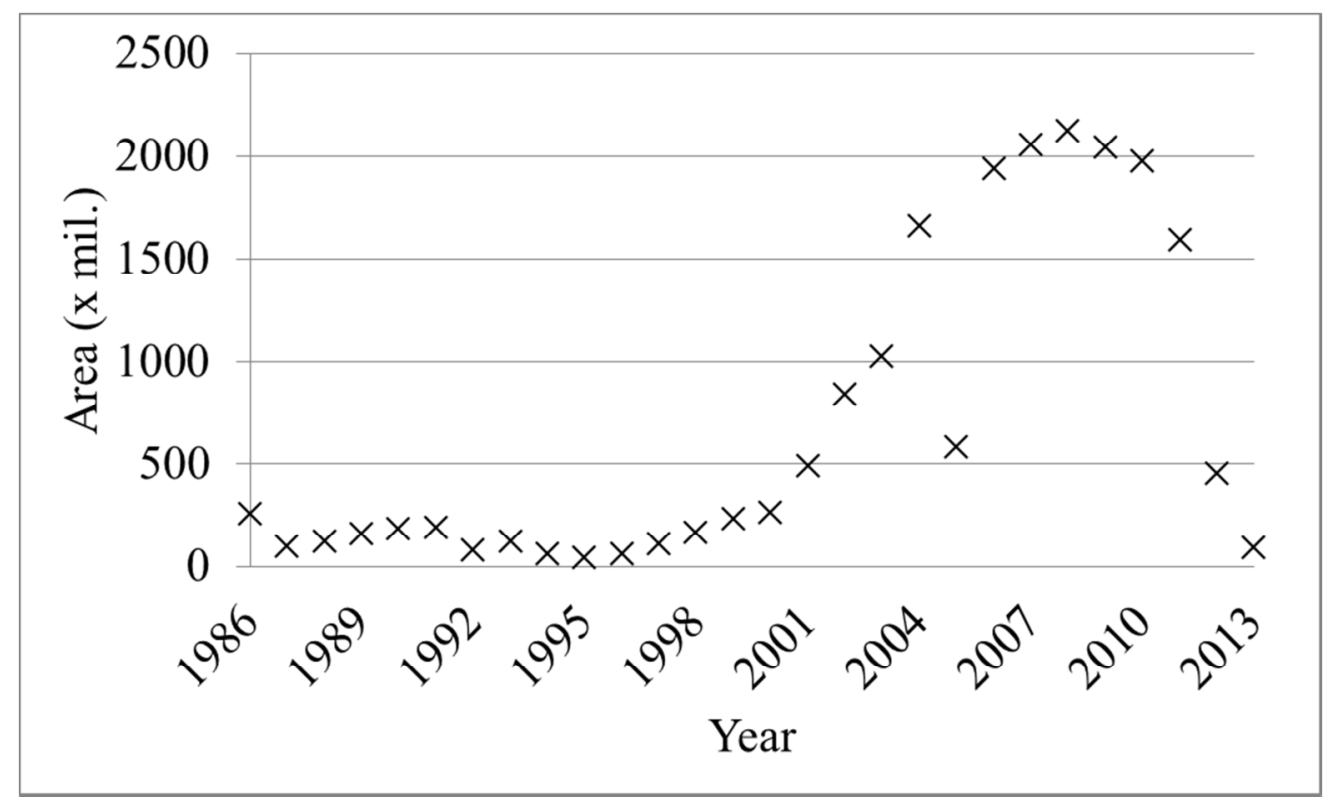

Figure 13: Quantified area of spider charts for cost variance at each year compared to the financial baseline

The yearly areas are then represented as spider charts as illustrated in Figure 14. Spider charts are used since these by default represent the data from a geometric perspective as illustrated in Figure 2. For ease of visualization and emphasis of the geometric perspective the vertex labels and the values of the vertices are removed. This also enables consideration of the topology independent of the applied coordinate system. To note is that the greater the relative size of a shape, the more interval lines connecting the vertices are visible. 


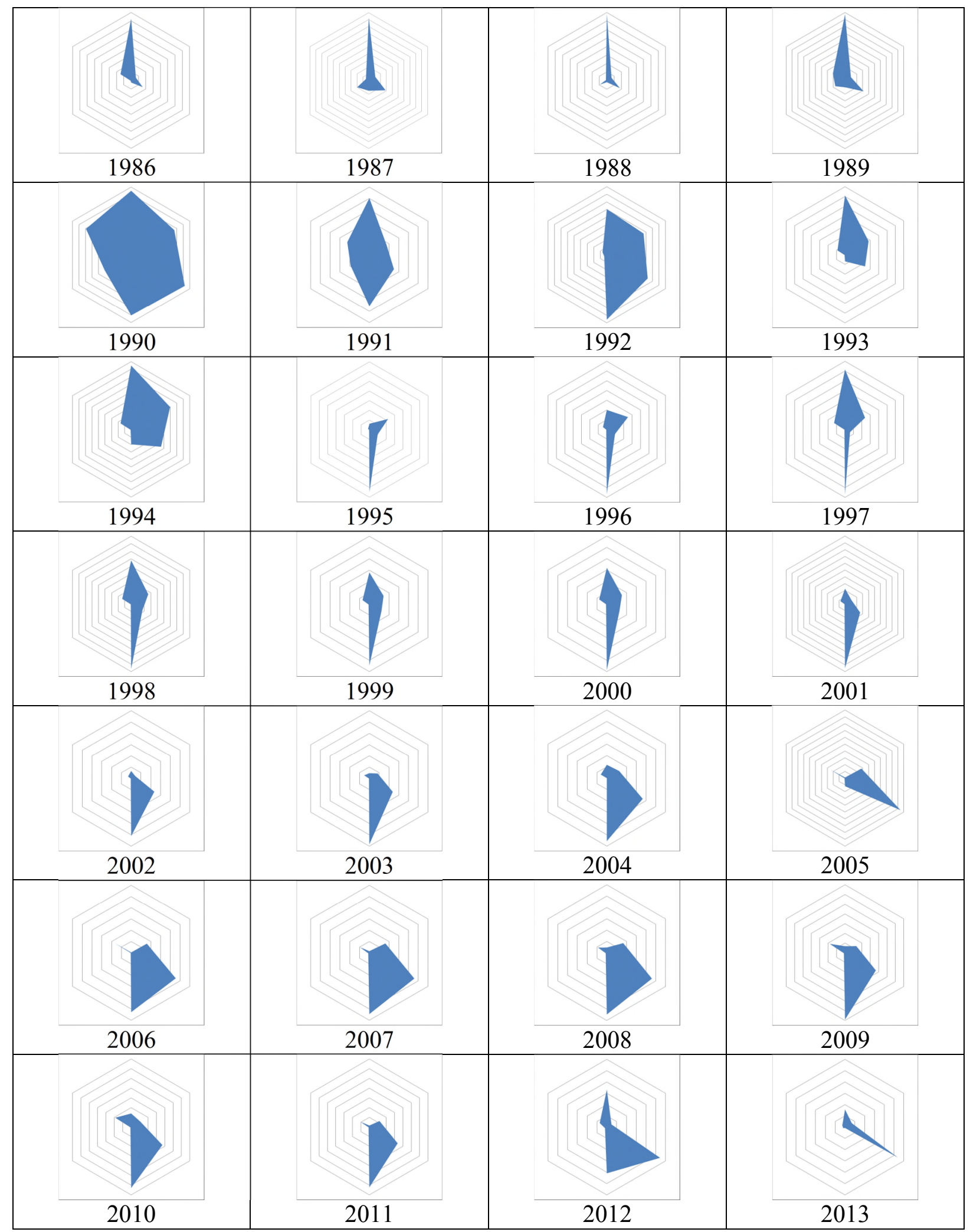

Figure 14: Yearly spider chart representations 
In order to connect the yearly representations these areas are then stacked as suggested by Figure 15.

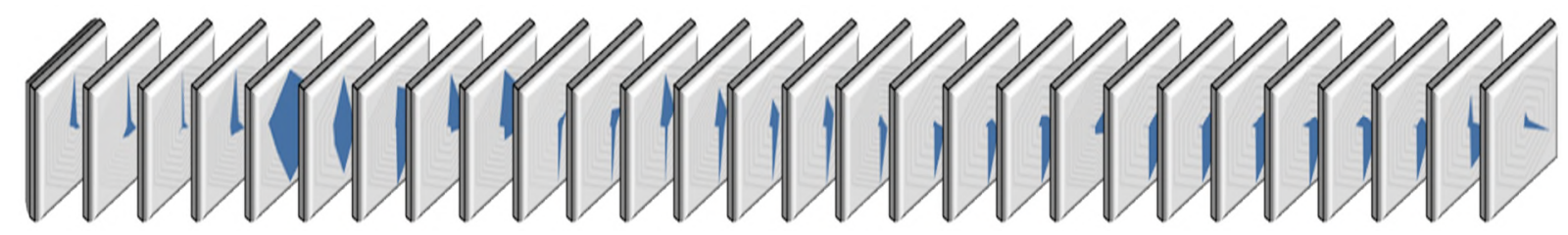

Figure 15: Exemplary spider chart stack

The spider chart thus creates a shape that can be visualized in threedimensions as illustrated in Figure 16 and Figure 17. In order to visualise the data from such a topological perspective individual spider chart values were first converted to a three-dimensional co-ordinate system as highlighted in

Table 8.

Table 8: Coordinate generation for each cost variance score

\begin{tabular}{ll}
\hline Axis & Value determination \\
\hline $\mathrm{X}$ & $\begin{array}{l}\text { Time in years from 1986-2013. } \\
\text { Actual cost variance value. Each value is adjusted to reflect a different " } 0 \text { " value } \\
\text { position due to the layout of the spider chart itself. }\end{array}$ \\
$\mathrm{Z}$ & $\begin{array}{l}\text { Physical graph distance between quantity, schedule, engineering, estimating, other, } \\
\text { and support. }\end{array}$ \\
\hline
\end{tabular}

A unique colour was assigned to each dimension for easing visual pattern recognition regarding these (Quantity: light salmon / Schedule: golden rod / Engineering: Lime Green / Estimating: turquoise / Other: thistle / Support: lemon chiffon). The attributes of each sphere ( $\mathrm{x}-, \mathrm{y}-, \mathrm{z}-\mathrm{axis}$ values, and sphere diameter) were then used to describe the object in a three-dimensional space visualised by a relevant graphical viewer / browser. 


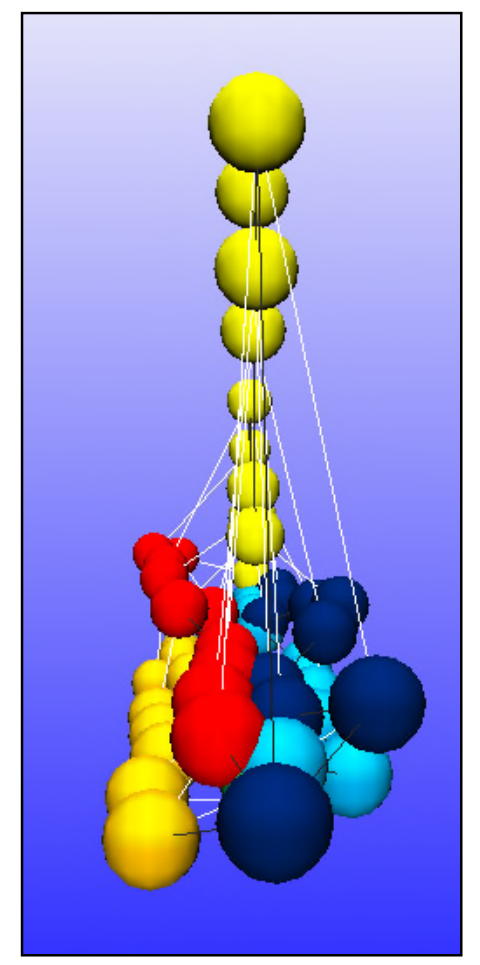

Figure 16: Exemplary three-dimensional visualisation (front view)

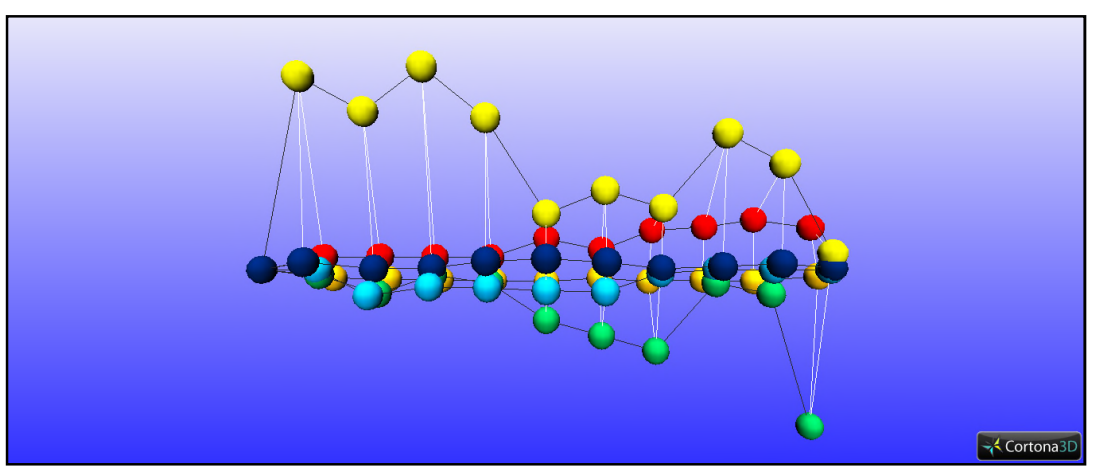

Figure 17: Exemplary three-dimensional visualisation (side view)

The overall compounded data volume of the shape (as illustrated in Figure 16 and Figure 17) was determined by compounding the data size for each time slice as illustrated by the scatter-gram in 


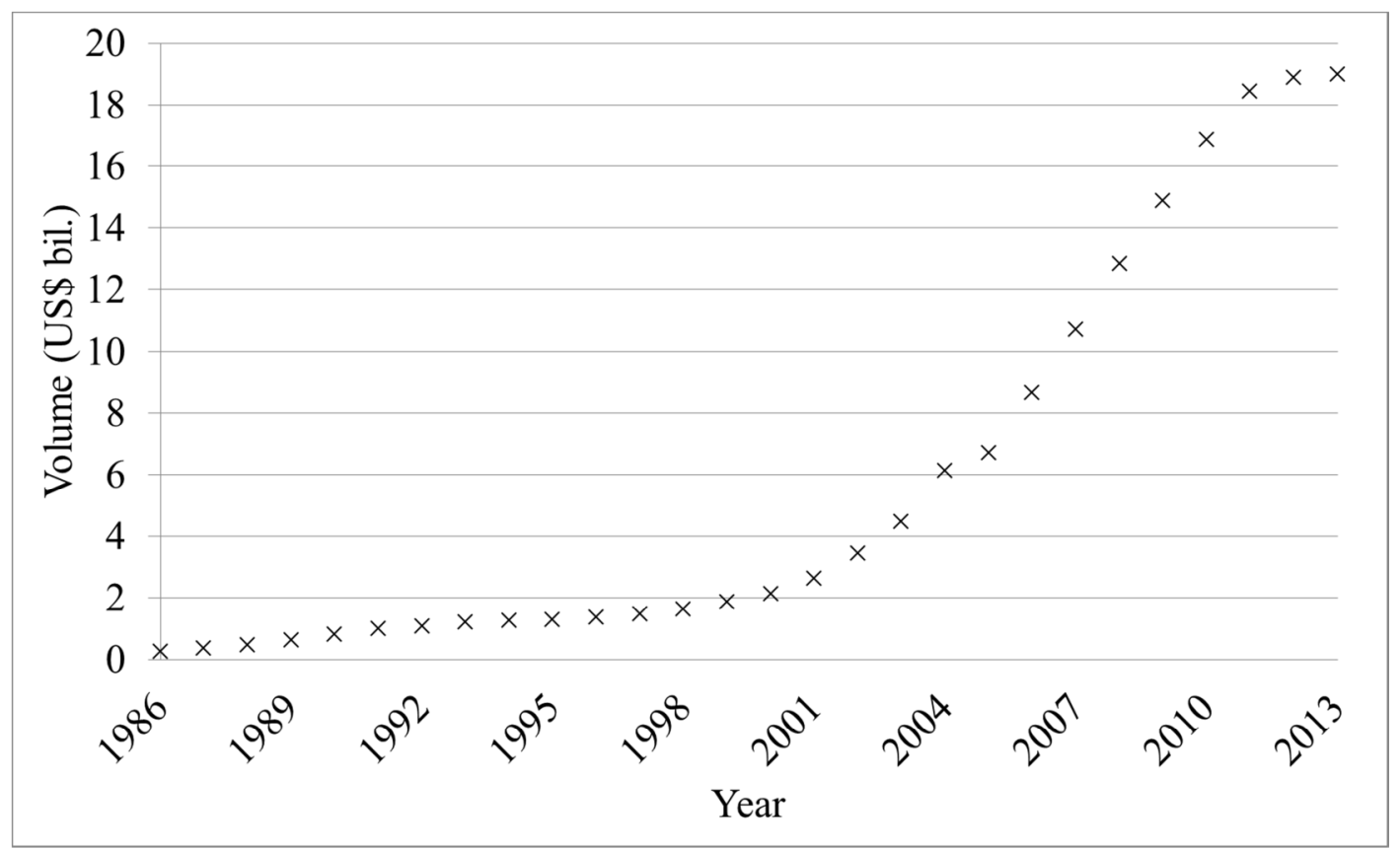

Figure 18.

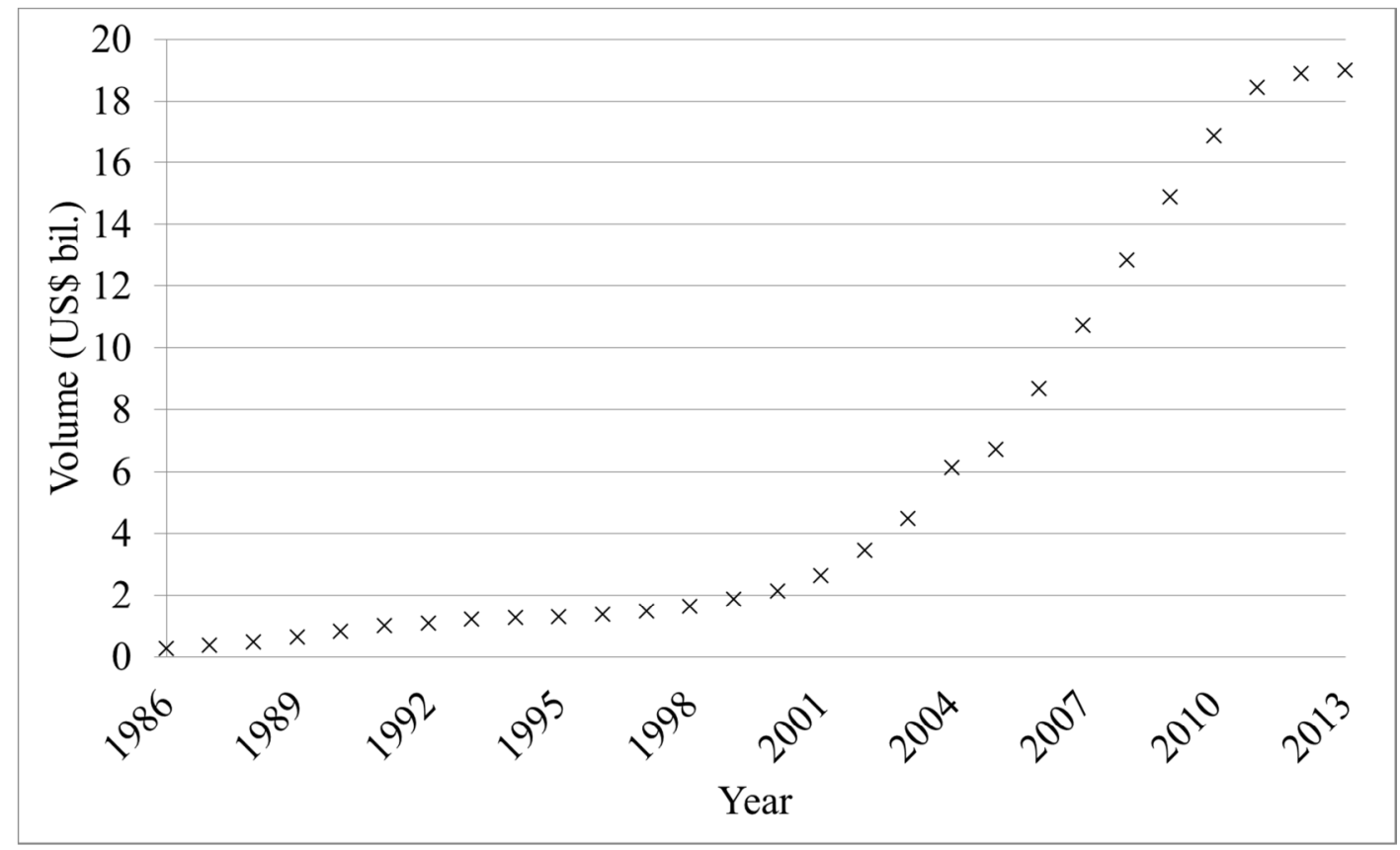

Figure 18: Compounded area (volume) of spider chart for cost variance at each year 


\section{Case study data correlation}

Applying the presented technique for the quantification of symmetry, the change in symmetry over time can now be determined. Figure 19 illustrates the change in symmetry for the case study data.

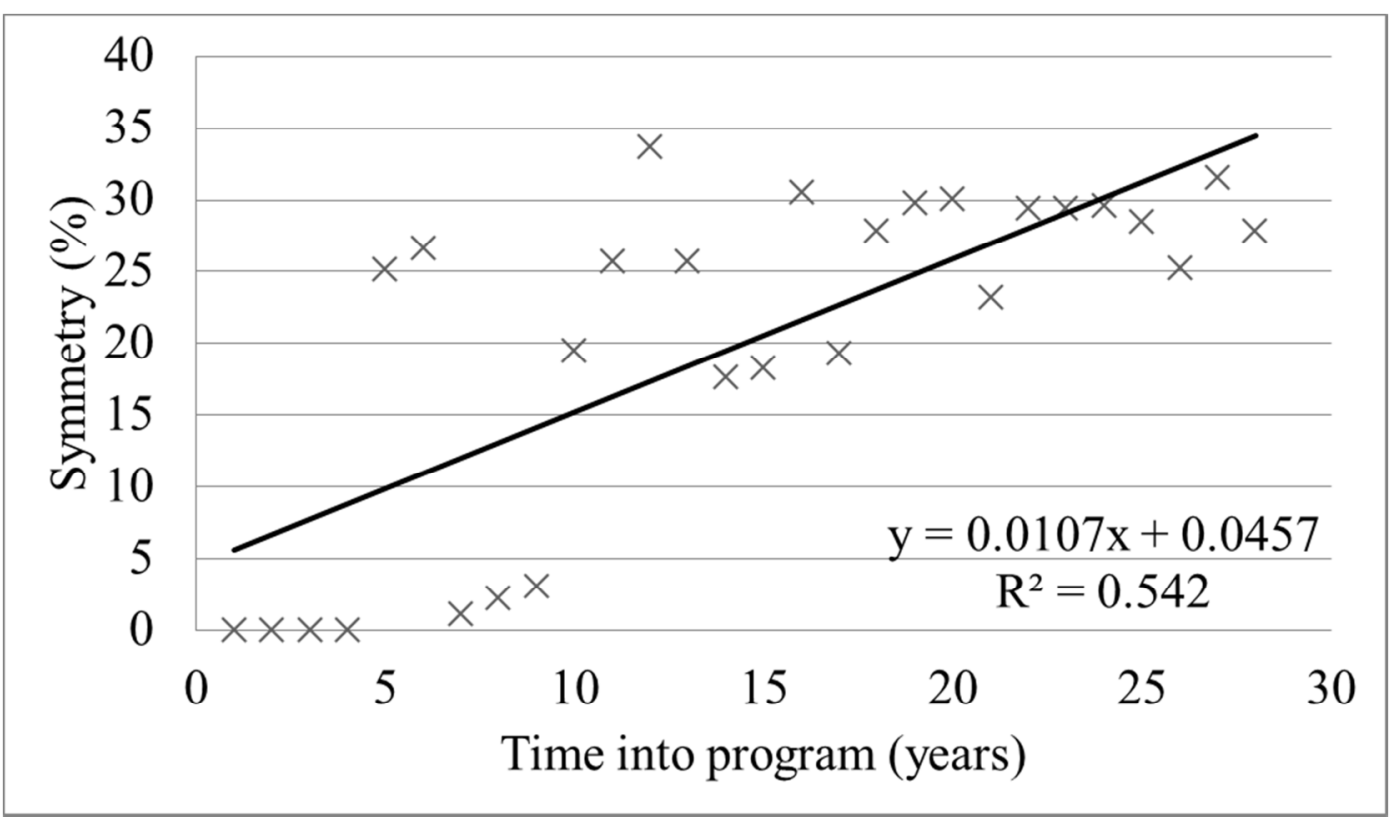

Figure 19: Change in symmetry over time

For every year into the future the symmetry is now assumed to follow the correlation equation of the linear trend-line $(y=0.0107 x+0.0457)$ and therefore, for the data context, increase annually by $5.64 \%$. While the authors agree that the low $\mathrm{R}^{2}$ value challenges the potential validity of this assumption the almost inherent 50/50 nature of the correlation appears to remain better than the accuracy of contemporary techniques applied in practice.

The symmetrical perspective can then be contrasted with the change in compounded cost variance over time as illustrated in 


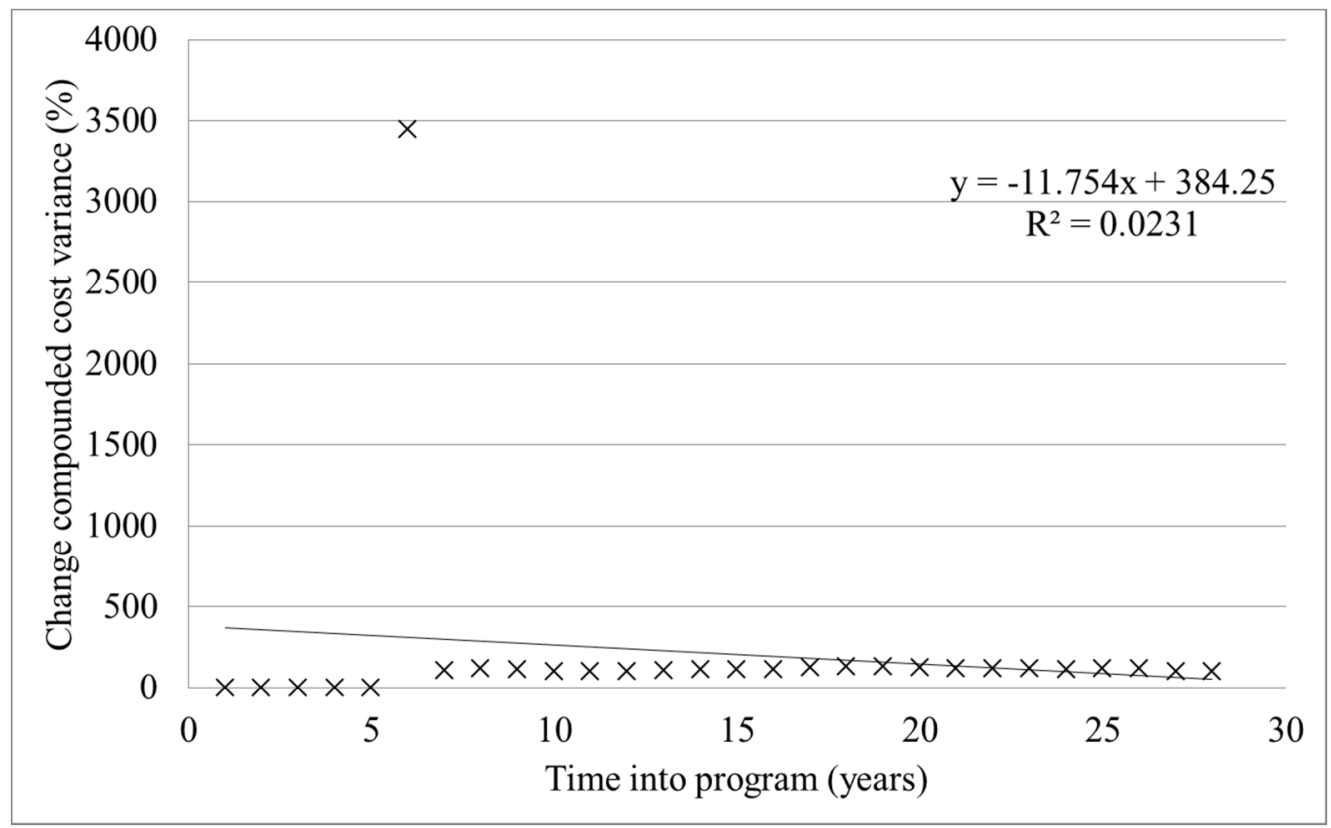

Figure 20.

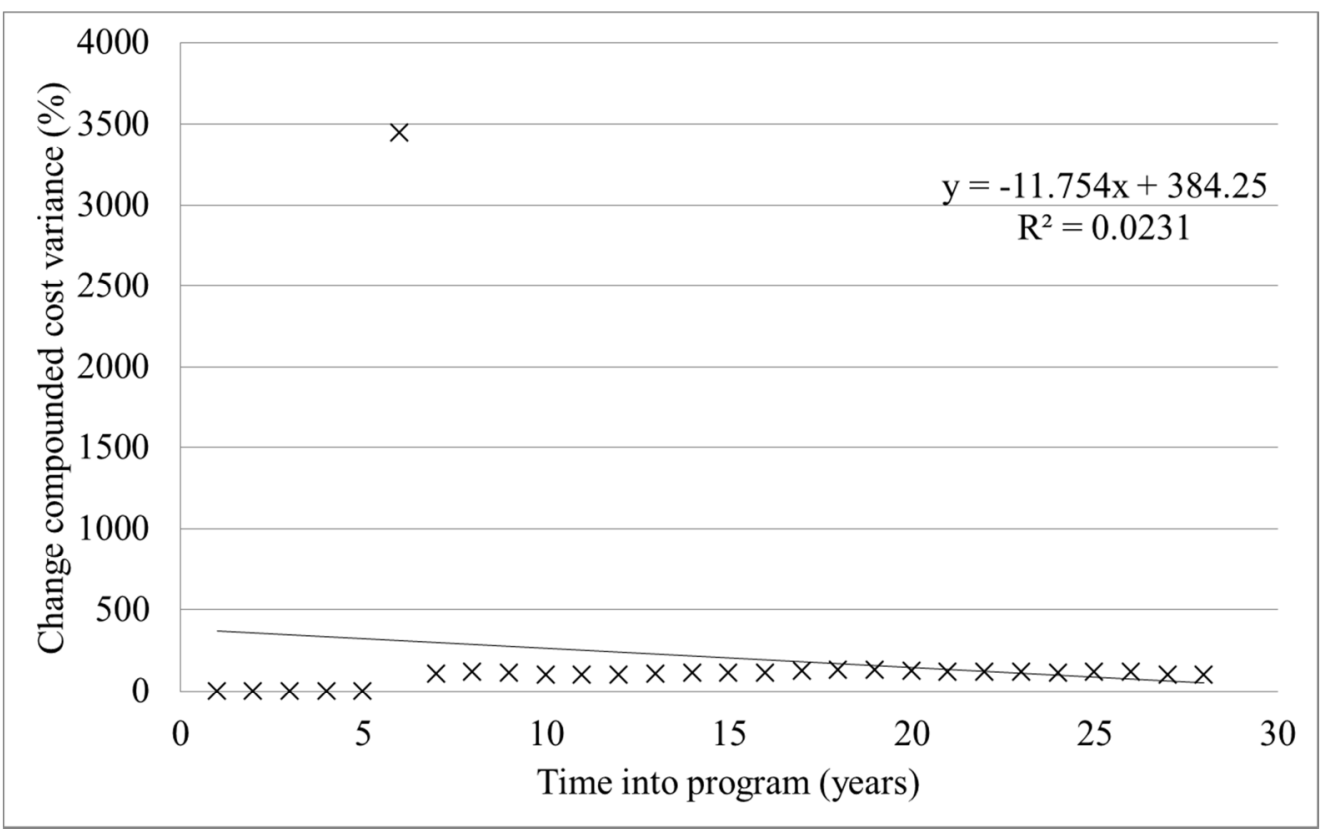

Figure 20: Change in compounded cost variance over time 
Since the data appears to contain an outlier at a time of six years into the program (with a $35 \%$ value for the change in compounded cost variance) this is set to 0 for purposes of further investigation with results as illustrated in

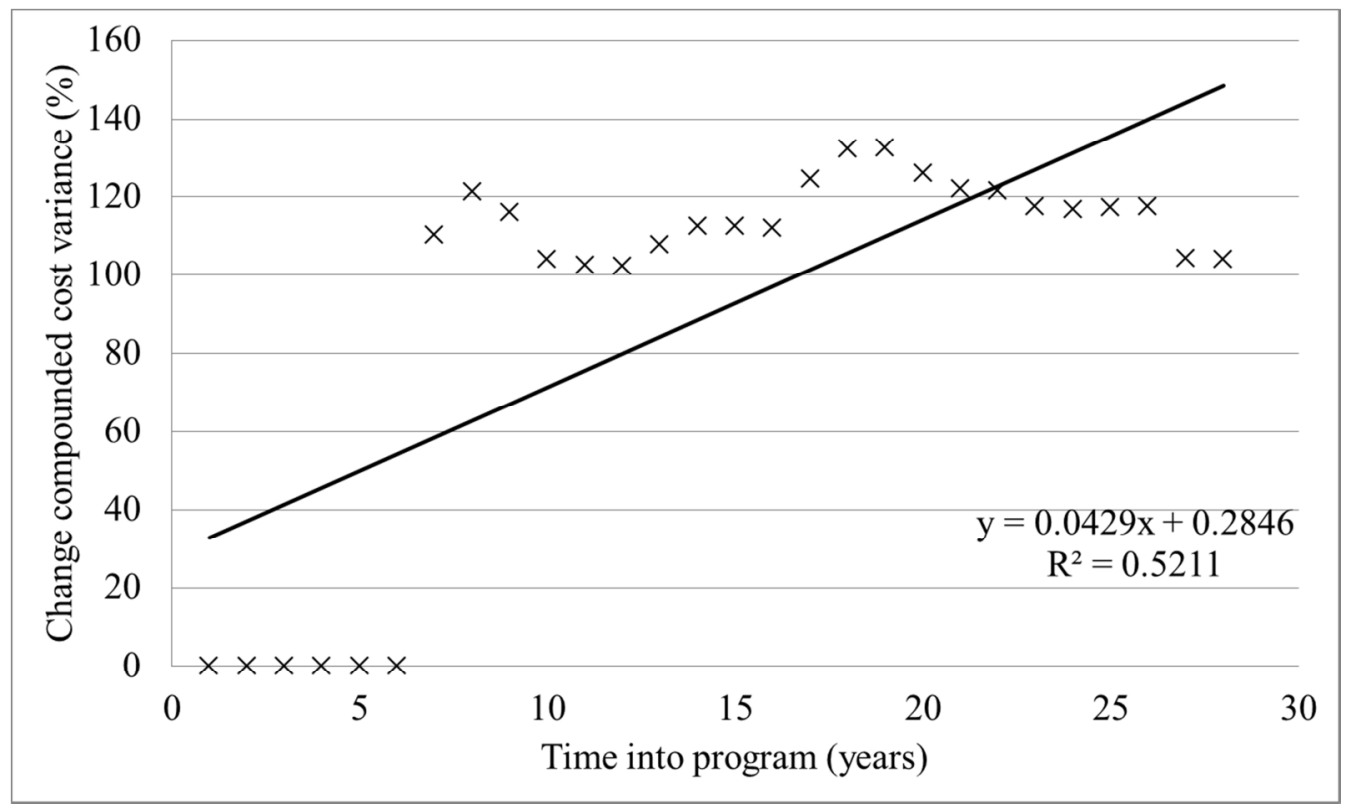

Figure 21.

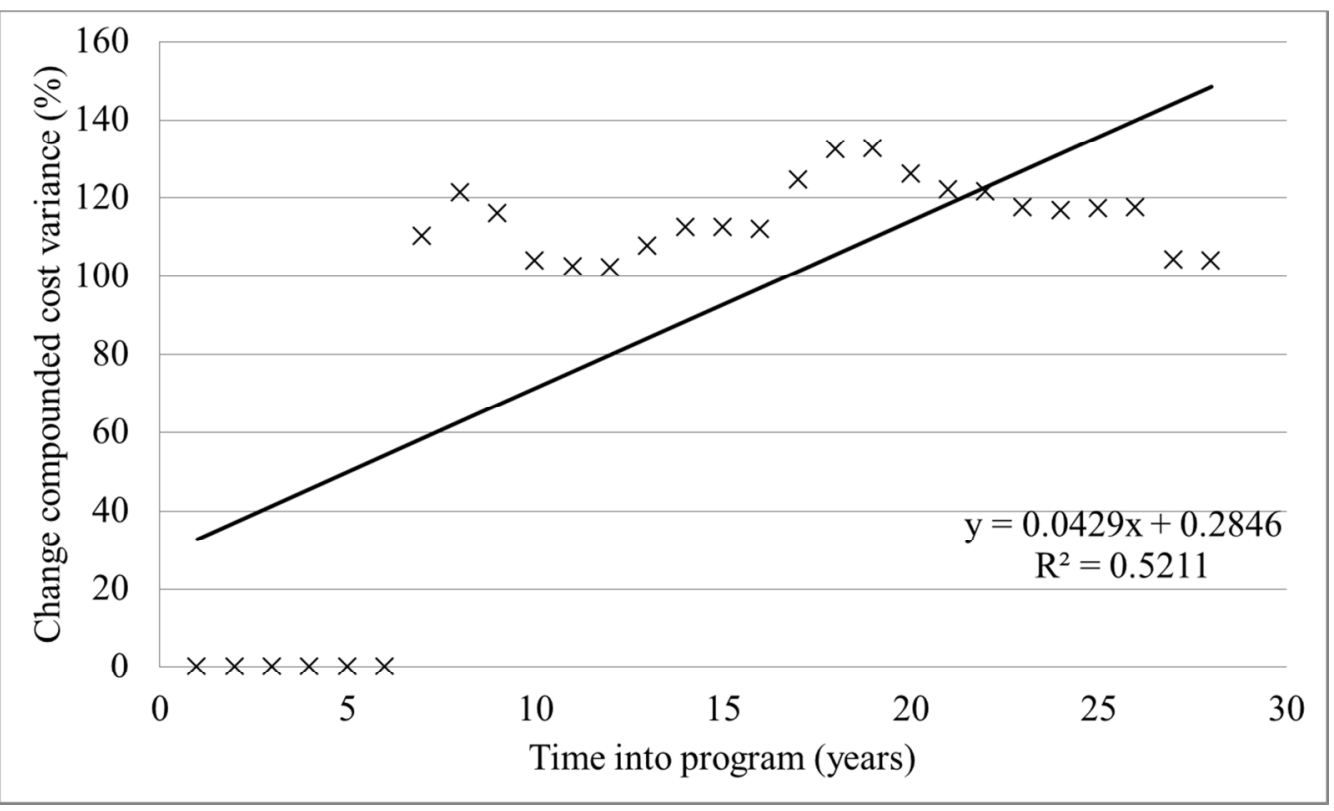

Figure 21: Change in compounded cost variance over time (single outlier removed)

Removing the outlier leads to a significantly higher $\mathrm{R}^{2}$ value $(0.5211)$. Moving forward with this result it can now be assumed that for every year into 
the future the change in compounded cost variance follows the correlation equation of the linear trend-line $(y=0.0429 x+0.2846)$ and therefore increases by $32.75 \%$ annually. For purposes of demonstrating the framework the step change between years six and seven is not examined further. Specific reasons for the step change could not be identified during the review of the case study data context and is subject to ongoing investigation.

Both the symmetry and the change in compounded cost variance increase over time with similar $\mathrm{R}^{2}$ values for the data drawn from the context. Based upon this an attempt at correlation can be performed, therefore to understand how symmetry and compounded cost variance are potentially related.

The two equations of relevance are:

- $\quad$ Symmetry (s): $y=0.0107 x+0.0457\left(\mathrm{R}^{2}=0.542\right)$

- Compounded cost variance $(\mathrm{ccv}): \mathrm{y}=0.0429 \mathrm{x}+0.2846\left(\mathrm{R}^{2}=0.5211\right)$

If compounded cost variance is proportional to symmetry then $0.0429 \mathrm{x}+$ $0.2846=\delta(0.0107 \mathrm{x}+0.0457)$ where $\delta$ represents the potential correlation factor.Resolving for $\delta$ in Equation 6 we arrive at:

$\delta=\left(\frac{0.0429 x+0.2846}{0.0107 x+0.0457}\right)$

Equation 6: Correlation factor for compounded cost variance and symmetry over time

For the evaluated 26 time periods between 1986 and 2013 the development of the propagation factor $\delta$ can hence be determined as illustrated by Figure 22 . 


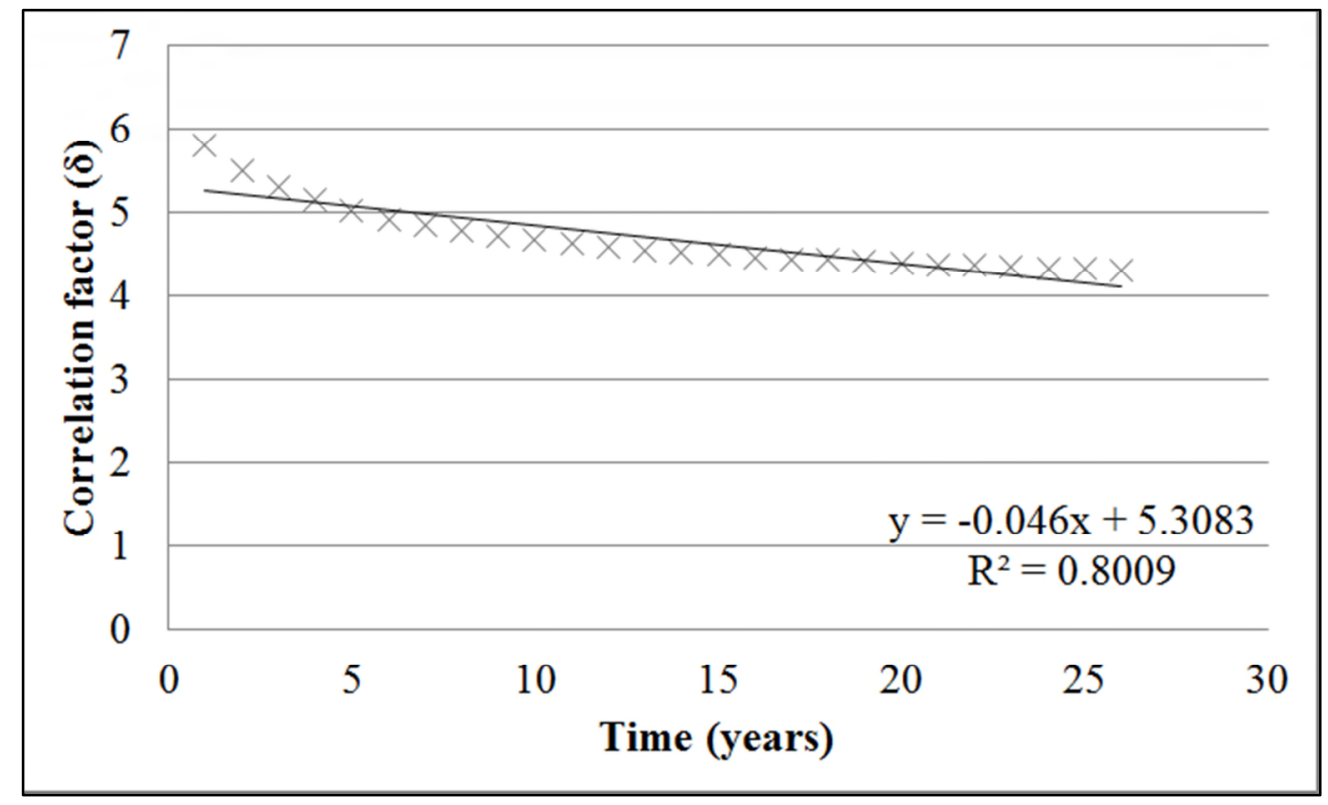

Figure 22: Correlation between compounded cost variance and symmetry over time

When interpreting Figure 22 the relatively high $\mathrm{R}^{2}$ value supports the declaration of symmetry as a metric for quantifying the value of cost uncertainty since similar results can be achieved through both perspectives. The meaning of such a high correlation in relation to the significantly lower correlations for symmetry and compounded cost variance is subject to ongoing investigation. To note is that the value of the correlation factor $(\delta)$ drops over time suggesting that the longer the forecast window the less dependable the correlation can be assumed to be.

As a result the hypothesis is raised that the value of the uncertainty of a cost estimate $n$ years after the creation of the financial baseline is given by Equation 7.

Value of Uncertainty Un $_{t=n}$ $=\left(\right.$ Technical Baseline Estimate $\left.* \delta_{t=n}\right)$

- Technical Baseline Estimate

Equation 7: Calculation of the value of uncertainty for $\mathrm{t}=\mathrm{n}$ 
Using data from the data context which was not used to develop the framework an initial application of the uncertainty quantification equation for $\mathrm{t}=1$ was performed whereby an average forecast accuracy of approximately $60 \%$ was achieved as illustrated in

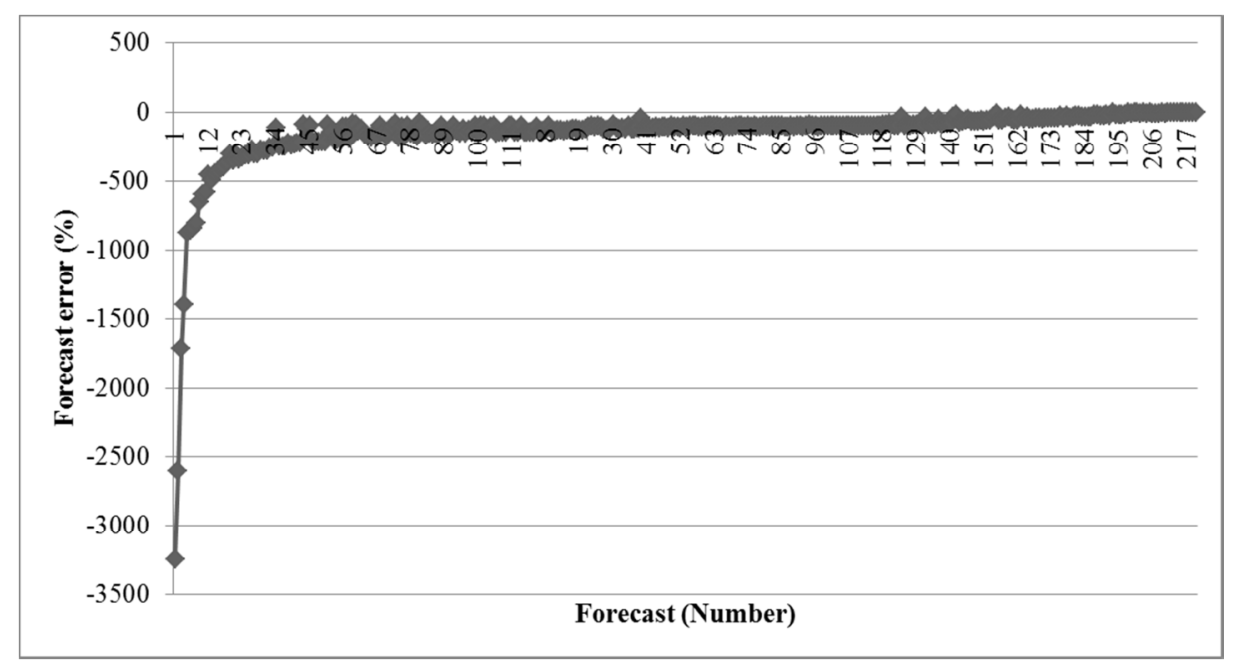

Figure 23. For this purpose the age of the technical baseline estimate was determined for 221 projects, for each project two consecutive years of data with an identical technical baseline estimate identified (forecastable events), the propagation factor $\delta$ determined for each such forecastable event for the older year, a forecast for the following year made using the equation for calculating the value of uncertainty for $\mathrm{t}=\mathrm{n}$, and then this result compared with the actual cost variance figures for that year.

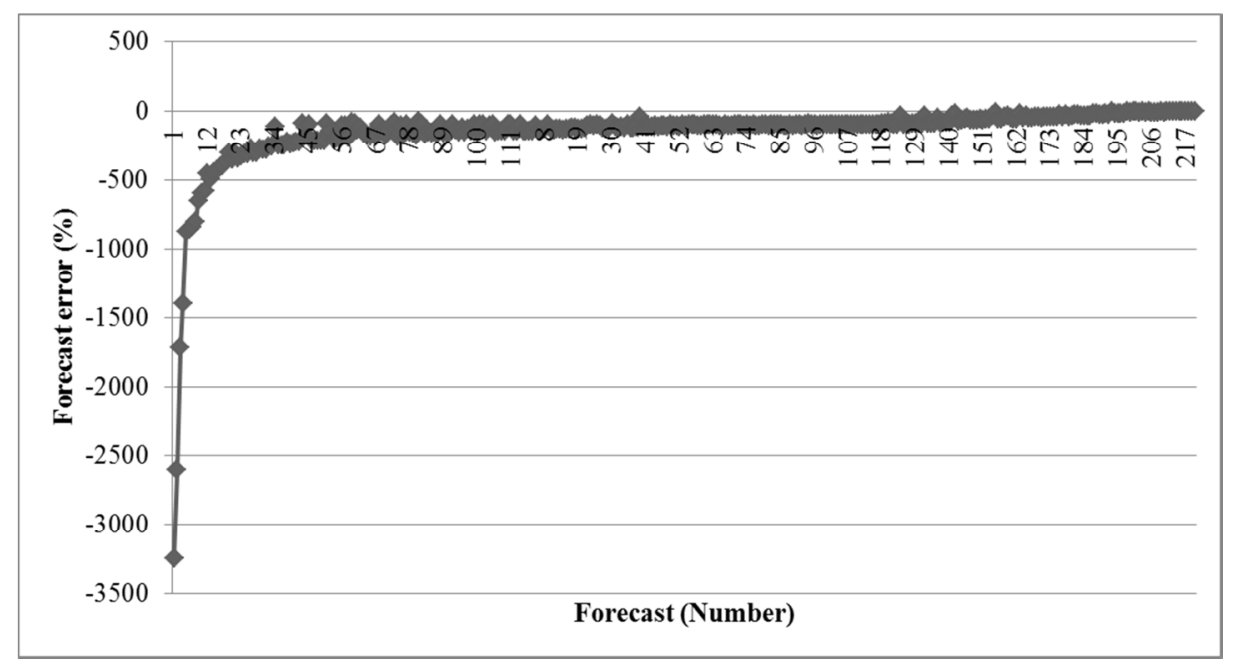

Figure 23: Forecast error results for $\mathrm{t}=1$ 


\section{Interdependency of cost variance dimensions}

Based on the analysis performed the investigation was continued to explore why the proposed correlation between compounded cost variance and symmetry might exist.

For this purpose the available historical cost variance data for multiple cost variance dimensions was correlated using the default linear trend-line function in MS ${ }^{\circledR}$ Excel. Based upon the correlation results a dependency diagram [43, 44] was created.

\subsection{Input output model}

The input output model illustrated in Figure 24 describes the data transformations completed. Based on the data available for absolute cost variance a regression analysis was performed in order to identify the correlation function between all cost variance variables. The slope of the linear correlation function was used to determine the value of future impact, while the co-efficient of correlation $\left(\mathrm{R}^{2}\right)$ is used to determine the sequence of impacts between the variables and their relative speed. Impact, sequence and speed can then be used to quantify cost variance propagation. 


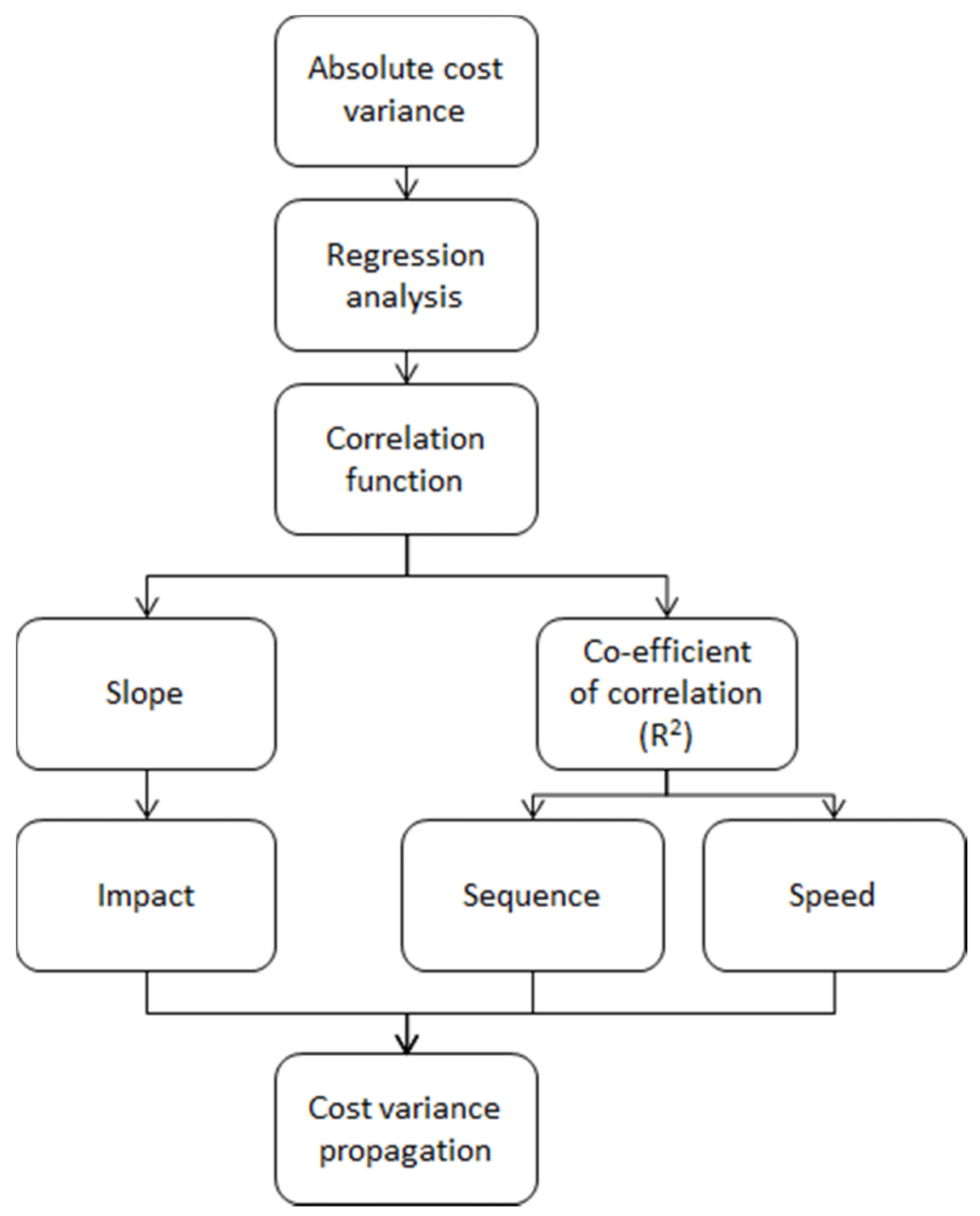

Figure 24: Input output model

\subsection{Correlation}

Sample input data is shown in Table 9 for the U.S. Navy CV Helo (SH-60F) with a financial base year of 1988 .

Table 9: Sample cost variance data

\begin{tabular}{|c|c|c|c|c|c|c|}
\hline Year & $\begin{array}{c}\text { Quantity } \\
\text { (US\$ mil.) }\end{array}$ & $\begin{array}{l}\text { Schedule } \\
\text { (US\$ mil.) }\end{array}$ & $\begin{array}{l}\text { Engineering } \\
\text { (US\$ mil.) }\end{array}$ & $\begin{array}{l}\text { Estimating } \\
\text { (US\$ mil.) }\end{array}$ & $\begin{array}{c}\text { Other } \\
\text { (US\$ } \\
\text { mil.) }\end{array}$ & $\begin{array}{c}\text { Support } \\
\text { (US\$ mil.) }\end{array}$ \\
\hline 1988 & 0 & 2 & 34 & 11 & 0 & 67 \\
\hline 1989 & 0 & 9 & 72 & 13 & 0 & 22 \\
\hline 1990 & 0 & 22 & 22 & 326 & 0 & 149 \\
\hline 1991 & 0 & 0 & 41 & 185 & 0 & 12 \\
\hline 1992 & 315 & 4 & 22 & 43 & 0 & 138 \\
\hline
\end{tabular}


While the consolidated cost variance data indicates which base data is to be used for experimentation it is critical to remember that the correlations are performed for the value of one variable at $t=0$ and the value of the second variable at $t=1$. In Table 10 these boundaries are indicated in an exemplary fashion by grey shaded cells.

Table 10: Sample cost variance data boundaries

\begin{tabular}{ccccccc}
\hline Year & $\begin{array}{c}\text { Quantity } \\
\text { (US\$ mil.) }\end{array}$ & $\begin{array}{c}\text { Schedule } \\
\text { (US\$ mil.) }\end{array}$ & $\begin{array}{c}\text { Engineering } \\
\text { (US\$ mil.) }\end{array}$ & $\begin{array}{c}\text { Estimating } \\
\text { (US\$ mil.) }\end{array}$ & $\begin{array}{c}\text { Other } \\
\text { (US\$ } \\
\text { mil.) }\end{array}$ & $\begin{array}{c}\text { Support } \\
\text { (US\$ mil.) }\end{array}$ \\
\hline & & & & & & \\
1988 & 0 & 2 & 34 & 11 & 0 & 67 \\
1989 & 0 & 9 & 72 & 13 & 0 & 22 \\
1990 & 0 & 22 & 22 & 326 & 0 & 149 \\
1991 & 0 & 0 & 41 & 185 & 0 & 12 \\
1992 & 315 & 4 & 22 & 43 & 0 & 138 \\
1993 & 616 & 7 & 69 & 214 & 0 & 241 \\
\hline
\end{tabular}

An example of a simple linear regression analysis is provided in Figure 25.

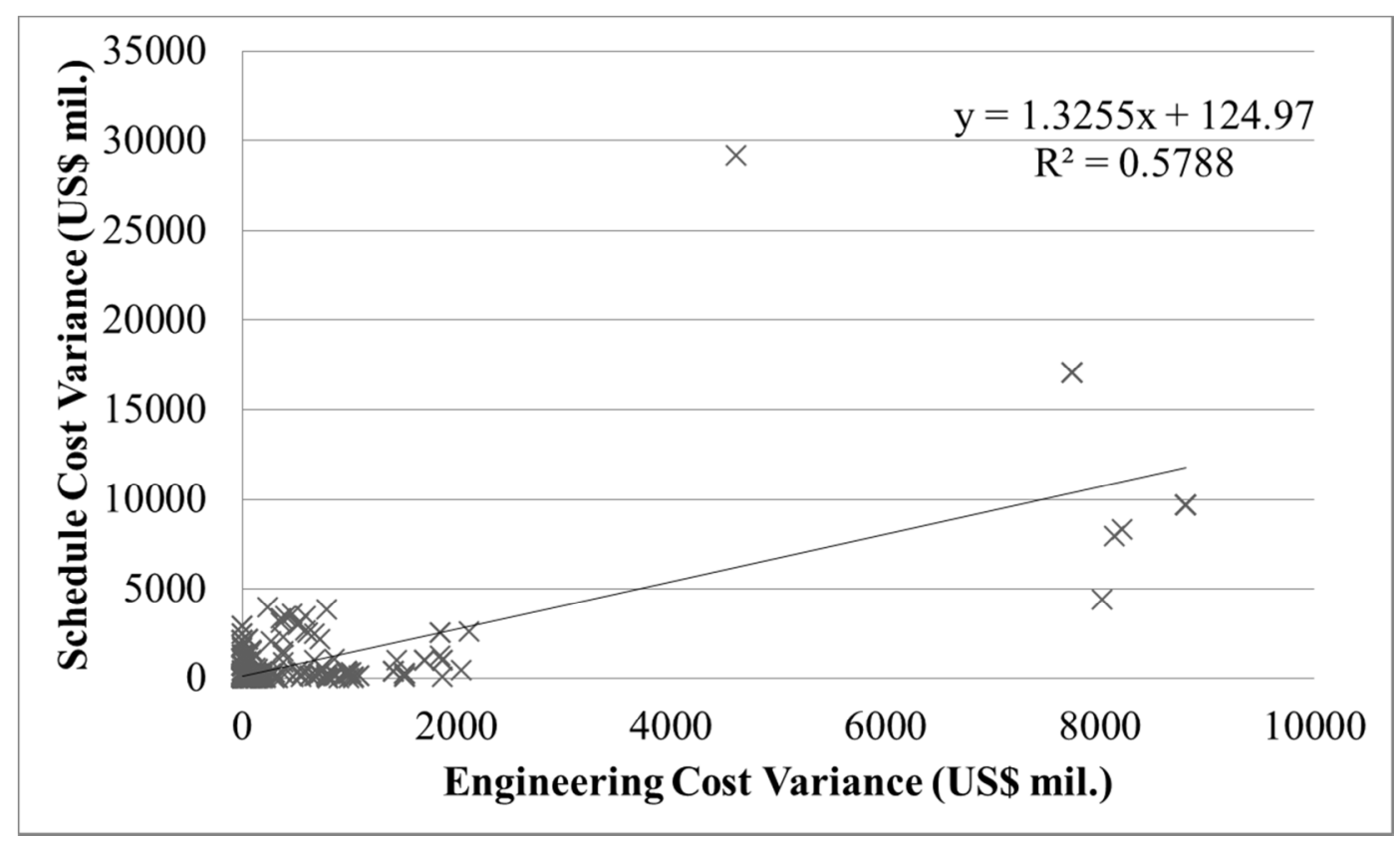

Figure 25: Exemplary engineering $t=0$ to schedule $t=1$ relationship (linear trend line only) 
The calculated correlations of all variable pairs to each other are listed in 
Table 11 
Table 11: Variable correlation

\begin{tabular}{|c|c|c|c|}
\hline Variable 1 & Variable 2 & Equation linear trend line & $\mathrm{R}^{2}$ \\
\hline Schedule & Engineering & $y=1.2578 x+214.99$ & 0.4368 \\
\hline Support & Engineering & $y=0.2178 x+316.13$ & 0.1824 \\
\hline Estimating & Engineering & $y=0.8416 x+1275.9$ & 0.1726 \\
\hline Quantity & Engineering & $y=0.0892 x+432.4$ & 0.0579 \\
\hline Other & Engineering & $y=-0.001 x+20.819$ & 0.0008 \\
\hline Schedule & Estimating & $y=3.4186 x+857.18$ & 0.4926 \\
\hline Support & Estimating & $y=0.0961 x+261.56$ & 0.2324 \\
\hline Engineering & Estimating & $y=1.2218 x+1336.2$ & 0.1959 \\
\hline Quantity & Estimating & $y=0.3338 x+1219.7$ & 0.1239 \\
\hline Other & Estimating & $y=0.0048 x+10.245$ & 0.1116 \\
\hline Estimating & Other & $y=0.0077 x+6.7607$ & 0.1724 \\
\hline Support & Other & $y=2.3829 x+409.37$ & 0.0307 \\
\hline Schedule & Other & $y=0.0057 x+18.759$ & 0.0064 \\
\hline Engineering & Other & $y=-0.0009 x+21.31$ & 0.0005 \\
\hline Quantity & Other & $y=0.0001 x+20.499$ & $6.00 \mathrm{E}-05$ \\
\hline Estimating & Quantity & $y=0.2477 x+1168.3$ & 0.1182 \\
\hline Support & Quantity & $y=0.0525 x+318.53$ & 0.0838 \\
\hline Schedule & Quantity & $y=0.0494 x+217.87$ & 0.07 \\
\hline Engineering & Quantity & $y=0.0791 x+375.8$ & 0.0576 \\
\hline Other & Quantity & $y=-0.0001 x+20.516$ & 0.0001 \\
\hline Engineering & Schedule & $y=1.2221 x+98.315$ & 0.572 \\
\hline Estimating & Schedule & $y=2.317 x+901.99$ & 0.431 \\
\hline Support & Schedule & $y=0.5539 x+237.26$ & 0.3886 \\
\hline Quantity & Schedule & $y=0.0611 x+247.5$ & 0.0824 \\
\hline Other & Schedule & $y=0.0053 x+18.014$ & 0.0068 \\
\hline Schedule & Support & $y=0.7329 x+249.66$ & 0.4441 \\
\hline Estimating & Support & $y=0.1644 x+201.46$ & 0.3338 \\
\hline Engineering & Support & $y=0.3277 x+313.76$ & 0.2764 \\
\hline Quantity & Support & $y=0.0605 x+355.16$ & 0.0797 \\
\hline Other & Support & $y=2.5022 x+455.82$ & 0.0255 \\
\hline
\end{tabular}

The results of the variable correlation are used to rank the degree of future impact based on the strength of the relationships between the variables in relation to the slope of the linear correlation line as illustrated in Figure 26. 


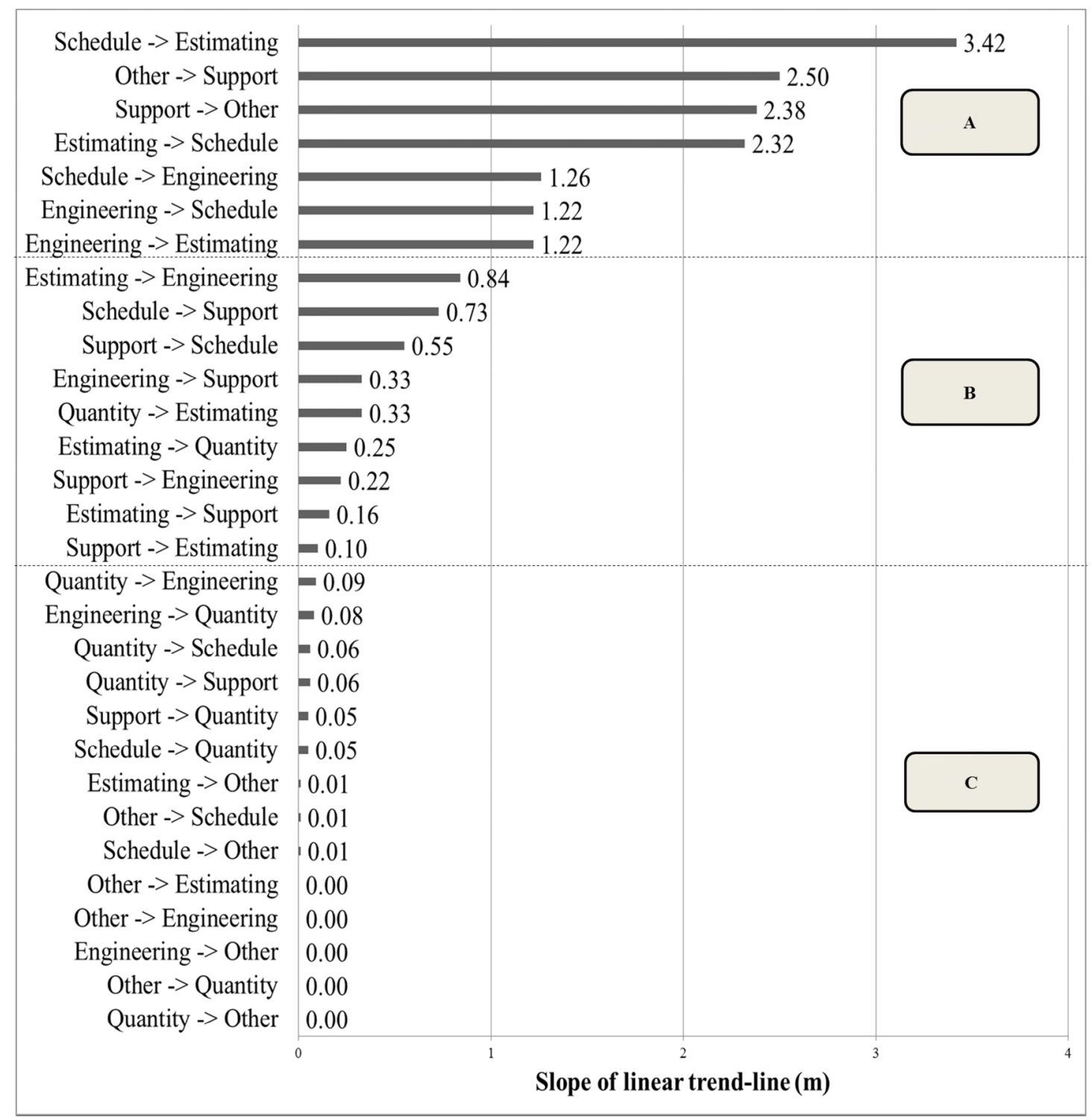

Figure 26: Correlation ranking: Degree of future impact

For variable pairs in area A the first variable grows faster than the second variable. For variable pairs in area $\mathrm{A}$ the second variable grows faster than the first variable. Variable pairs in area $\mathrm{C}$ are disregarded since their value at one decimal point accuracy is zero.

The results of the variable correlation can then be used to rank the sequence of the relationships between the variables based on the correlation co-efficient $\left(\mathrm{R}^{2}\right)$ of the linear correlation line. It is assumed that the greater $\mathrm{R}^{2}$ the stronger / more dominant the correlation 
and that $\mathrm{R}^{2}$ can therefore be used for determining sequence of impacts. This is illustrated in

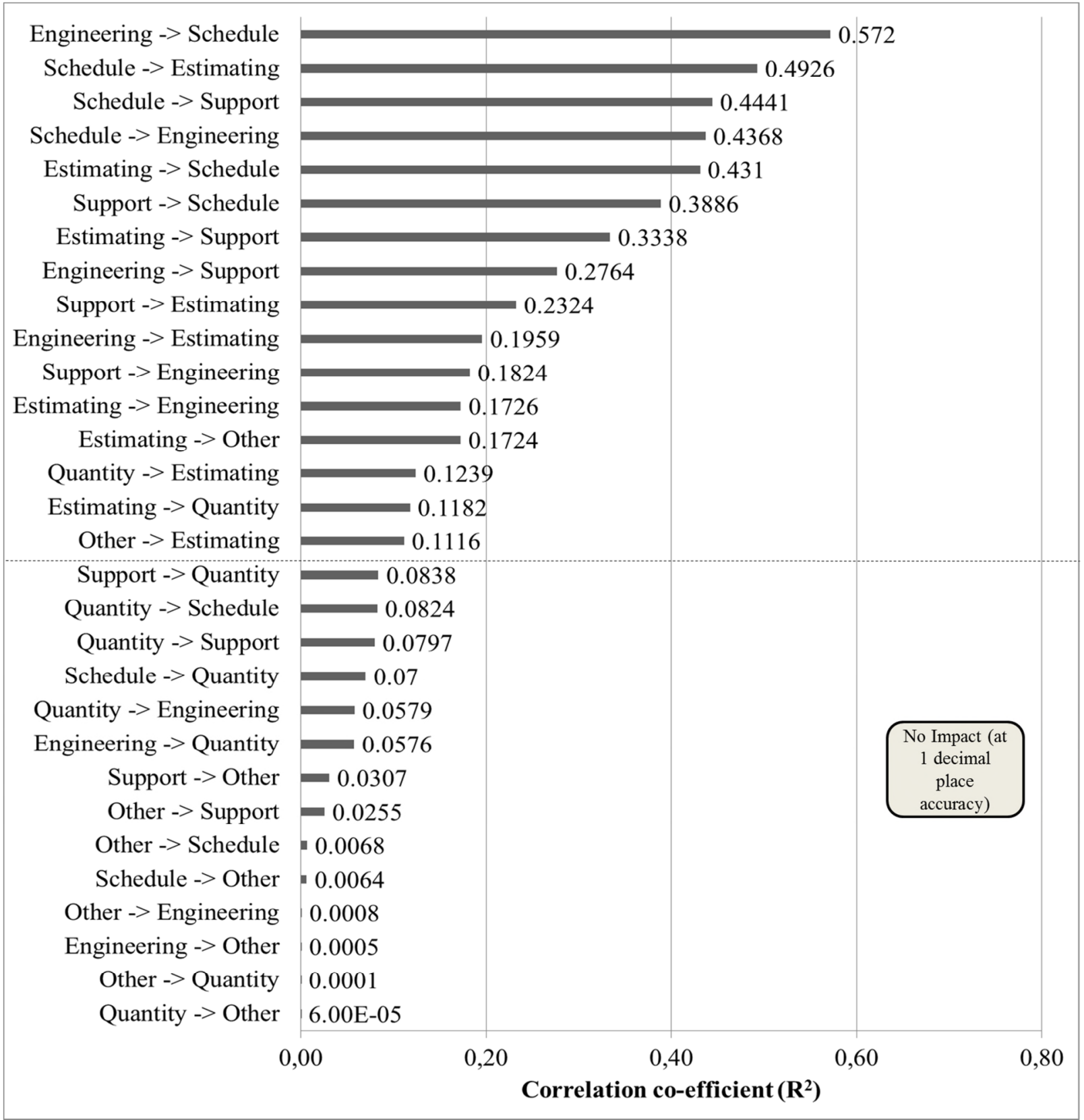

Figure 27. For purposes of simplification relationships with strength of 0 at 1 decimal place accuracy were disregarded and sequence equated with speed. 


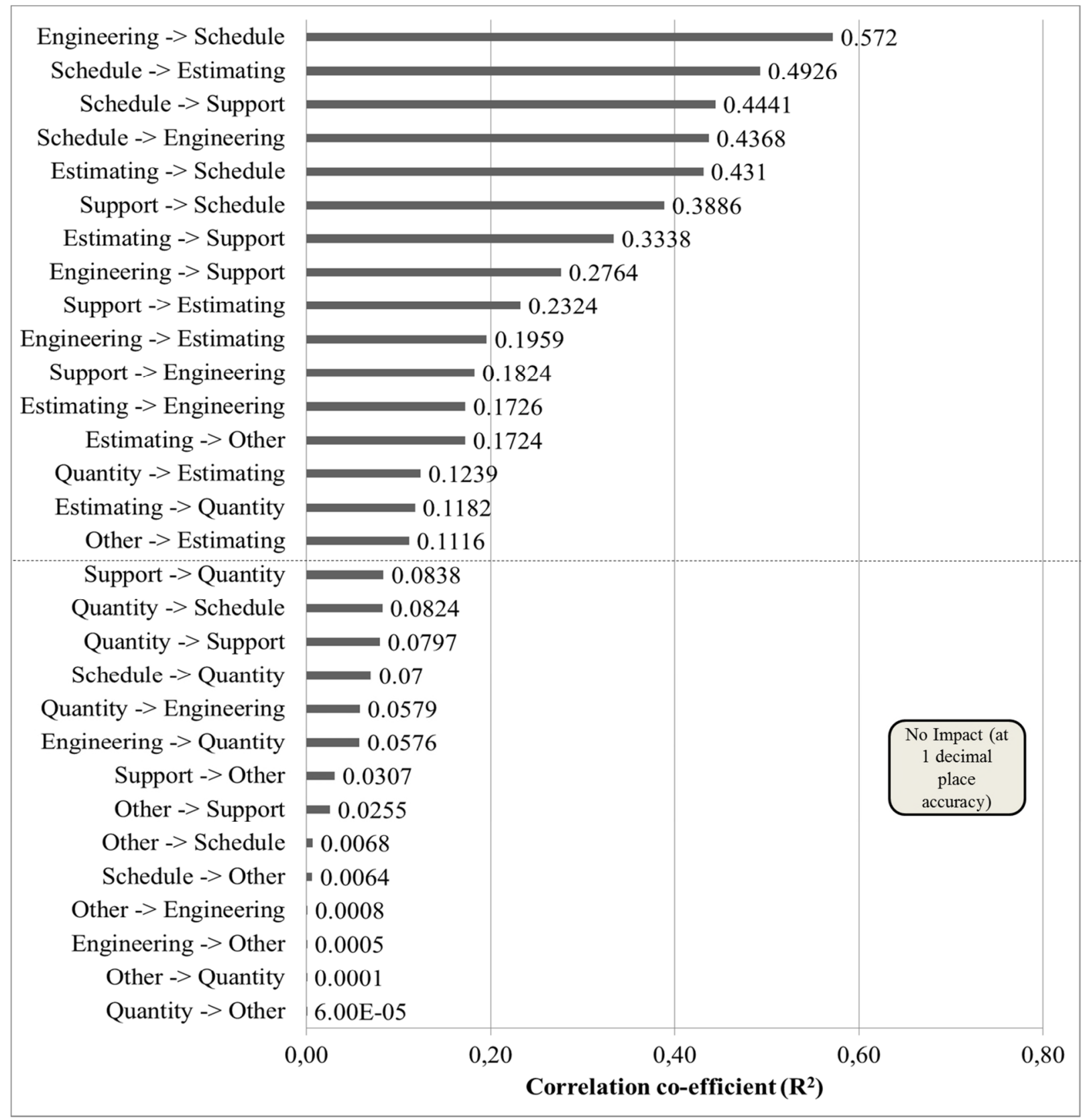

Figure 27: Correlation ranking: Speed and sequence of future impact

\subsection{Dependency model}

Based upon the correlation rankings for the degrees of future impact, speed and sequence a dependency model can be created as shown in Figure 28. 


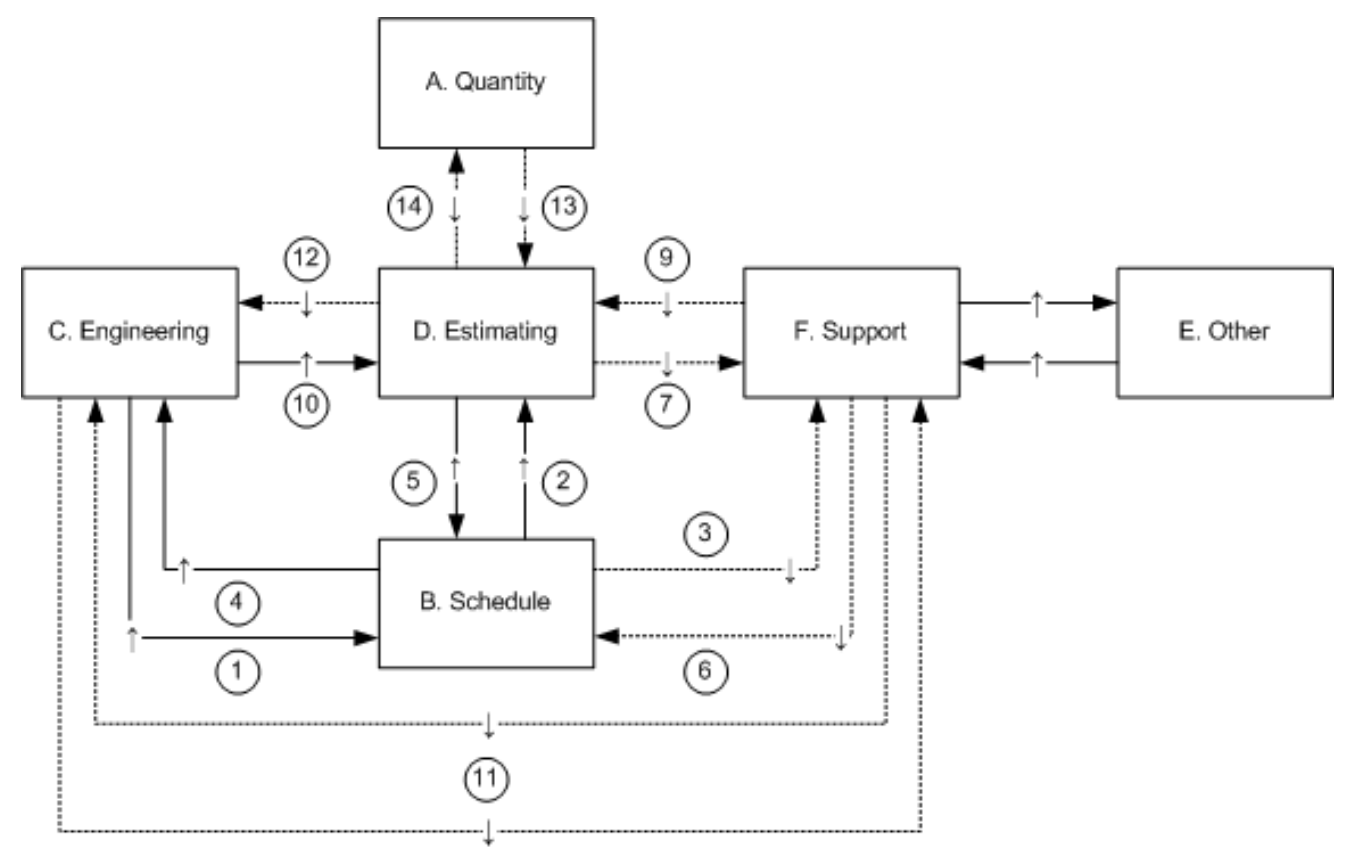

(8)

Figure 28: Dependency model

The arrows indicate from which factor an input arises / to which factor an output is delivered, and the numbers indicate the sequence of these inputs / outputs within the simulation. A dotted arrow / " $\downarrow$ ” symbol indicate a decreasing influence (therefore the impacted variable grows slower than the triggering variable - decelerated variance) and a solid arrow / “个” indicating an increasing influence (therefore the triggering variable grows faster than the impacted variable - accelerated variance). In this respect each cost variance variable can now be described based upon inputs and outputs including the sequence of these being generated or received.

The dependency model can then be simulated to determine the propagation of cost variance (therefore manifested cost variance) over time. As illustrated in Figure 29 the forecast indicates an exponential growth curve, whereby the values are suggested to represent the range of uncertainty that may be encountered. 


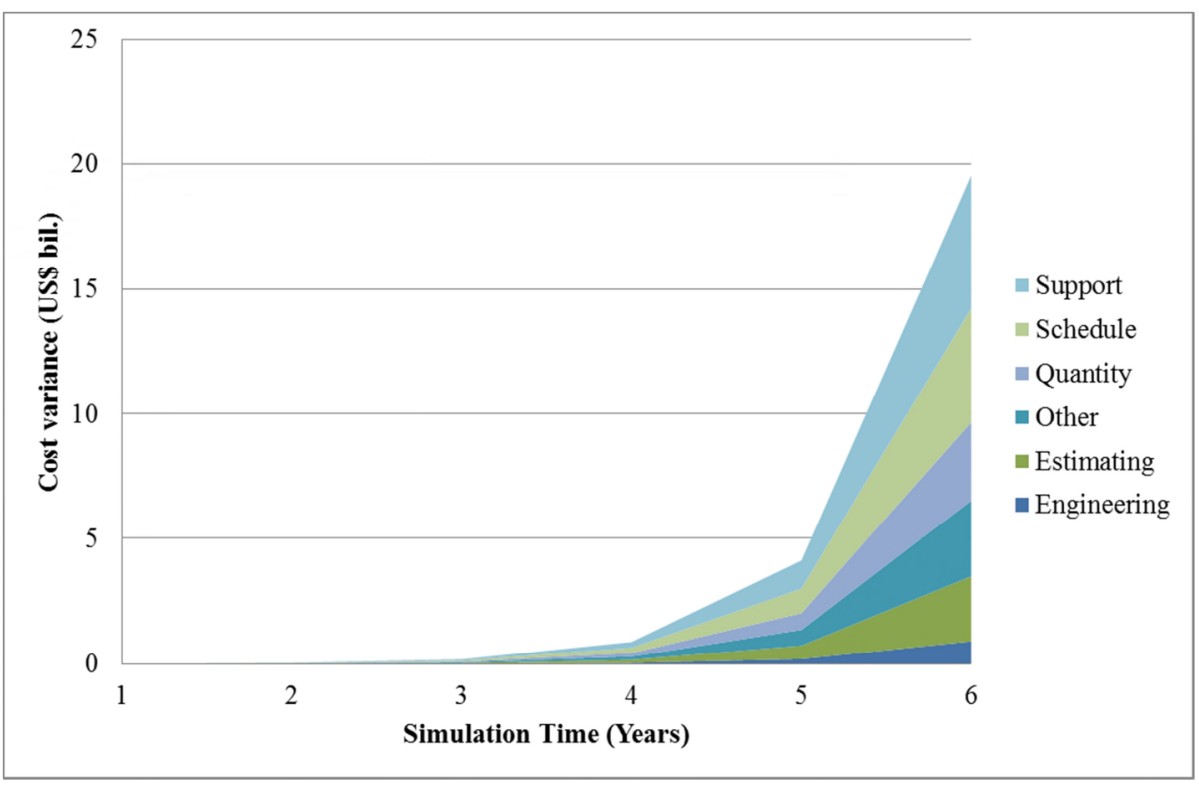

Figure 29: Total cost variance propagation based on dependency model

The growth curve suggests growth properties of cost variance (therefore manifested uncertainty) which may be dampened or interrupted by interventions, yet will always return to their behaviour if left unattended. This growth curve can then be described as the growing range of uncertainty for a cost estimate over time.

\subsection{Expert interviews}

In order to validate the conceptual soundness of the framework as a whole and in particular to reflect critically on the axioms introduced to support the framework a series of expert interviews were completed. Replies were followed up via email, in face-to-face and/or telephone interviews. Seventeen interviews were conducted with experienced cost estimation professionals representing four aerospace manufacturing companies, one solution provider for parametric cost estimation tools, one automobile manufacturer and two cost estimation associations. The interviewed individuals were all professionally concerned with the identification or development and promotion of leadingedge technology for which pertinent historical information is often lacking or hidden in archives that are not easily accessible.Roles assumed by and industries belonging to interviewees are listed by Table 12 .

Table 12: Roles, professional experience and industries of interviewees 


\begin{tabular}{|c|c|c|}
\hline Role & Professional Experience (Years) & Industry \\
\hline Actual Cost Reporting Expert & 15 & Aerospace Manufacturing \\
\hline Chief Cost Engineer (Business Unit) & 13 & Aerospace Manufacturing \\
\hline Chief Cost Engineer (Software) & 25 & Aerospace Manufacturing \\
\hline Chief Cost Estimator & 20 & Automobile Manufacturing \\
\hline Cost Estimating Expert & 12 & Cost Estimation Solutions \\
\hline Cost Estimating Expert & 13 & Aerospace Manufacturing \\
\hline Cost Estimating Expert (Whole Engine) & 18 & Aerospace Manufacturing \\
\hline Engineering Simulation Specialist & 14 & Aerospace Manufacturing \\
\hline Enterprise BCM Director & 12 & Aerospace Manufacturing \\
\hline Enterprise Risk Director & 15 & Aerospace Manufacturing \\
\hline Finance Director & 16 & Power Generation Industry \\
\hline Finance Director & 18 & Power Generation Industry \\
\hline New Product Introduction Expert & 11 & Aerospace Manufacturing \\
\hline Product Life Cycle Expert & 22 & Aerospace Manufacturing \\
\hline Product Portfolio Manager & 23 & Aerospace Manufacturing \\
\hline Regional Risk Director & 13 & Aerospace Manufacturing \\
\hline Robust Simulation Team Lead & 15 & Aerospace Manufacturing \\
\hline
\end{tabular}

Interview questions posed were:

- How relevant is the challenge addressed to your organisation?

- Are the axioms introduced acceptable for purposes of the investigation?

- How familiar are you with the use of spatial geometry in estimation?

- Does the framework appear to be a reasonable alternative to cost estimating techniques you use in your organisation? 
Overall the interviewees considered the concepts of spatial geometry and symmetry as being relatively foreign to their professional practice. Furthermore foreign was the use of the term "dimensions" to describe the elements of a cost estimate (i.e. engineering, quantity, or schedule). The focus on the factors of cost variance versus the actual cost variance also led to diverse misinterpretations since this is not standard practice in cost estimation. Specific feedback received can be summarized as follows:

- The problem addressed is relevant since as highlighted by one interview participant "...quantifying the relationship between the accuracy of an estimate and the timescale to which it applies is a very pertinent effort when one considers that some estimates are for 25 years or more."

- It was generally agreed that “... the amount of model review and calibration that is performed across many industries is inadequate and limiting the degree to which organisations learn by experience."

- The axioms represent an acceptable starting point for the framework although "... the (un-) certainty of the estimate needs to be clearly separated from the accuracy of the estimate in that we can be highly certain about the inaccuracy of an estimate as well."

- One participant suggested that “...the separation of the concepts of certainty and confidence is an important point to consider in order to avoid confusion between subjective and statistical perspectives."

Further relevant perspectives raised during the interviews were:

- It is important to understand what degree of accuracy is appropriate to the question being investigated, i.e. an accuracy of four decimal points is irrelevant if the results can only be validated at one decimal point accuracy.

- Time-delayed impacts on cost variance are generally not considered in estimation yet deserve further consideration. A suitable analogy might be drawn to a stone dropped in the water where the "ripples" expand symmetrically in all directions with fluctuating value.

- The simulated behaviour suggests long tail characteristics of the point cloud data over time. 
- The estimation discussion needs to be honest in respect that “...true cost cannot be knowable when the estimate is made owing to future variations in business and economic factors and the essential imprecision of all of the factors under consideration".

\section{Discussion}

\subsection{Results comparison}

The only data set identified by the researchers which is potentially suited for comparing the forecasting results of the framework against can be found in the United States Joint Agency Cost Schedule Risk and Uncertainty Handbook [11] which not only provides a state-of-art overview of cost estimation approaches, including the treatment of risks and uncertainties, but also includes a spectrum of detailed mean cost growth factors of SARs for forecasting at various milestones in the whole product life cycle, for various types of products and mission paths. The latter are suggested based on regression analysis of data since 1969, 1980 and 1990 using the NCCA S-Curve Tool [44]. Due to the significant number of differences between the manners in which growth factors are determined, as illustrated in Table 13, the authors however rule out a direct comparison of forecasting accuracy at this point.

Table 13: Comparison of growth factor determination approaches

\begin{tabular}{ll}
\hline \multicolumn{1}{c}{ NCCA SAR Growth Factors } & \multicolumn{1}{c}{ Geometrical Framework } \\
\hline Based on data for 1969-2011, 1980-2011 and & Based on the time period between 1986 and \\
1990-2011. & 2013. \\
Starting conditions are milestone, product, & Starting conditions are time of estimate and \\
mission path and aggregated force level / total net & project level absolute cost variance for individual \\
cost variance data. & cost variance dimensions. \\
Does not consider individual cost variance & Considers sensitivities of individual cost variance \\
dimensions. & dimensions. \\
\hline
\end{tabular}

\subsection{Limitations}

Any new method requires careful reflection on the limitations involved and the degree that these may influence the results of the method. Potentially significant limitations identified during the investigation are: 
- Visualise:

- Data context: Only one data context was examined and the degree that the findings can be generalised at this point is unclear.

- Data topology: A change in the number of cost variance dimensions reported on was considered a change in the invariant topological characteristics and hence preventing comparison with other topologies of differing invariant characteristics.

- Data boundaries: Boundaries were based upon topological considerations (i.e. identically reported cost variance dimensions) which prevented comparison to other investigations.

- Data coherence: The case study data was not differentiated based on the number of units, the novelty, the life cycle phase, the financial volume, the mission path, or the number of suppliers involved.

- Reference shape: The choice was based on the assessed cost variance dimensions which may impact generalisation and the influence of " 0 " scores in any dimensions was not investigated.

- Quantify:

○ Data context: Financial figures were available only for project phases related to the SARs (therefore those that have already exceeded permitted variance ranges).

- Analytical simplification: Data aggregation was performed at project level and only linear regressions were used.

- Geometrical attributes: Advanced metrics were not considered.

○ Propagation: The applicability of information entropy principles was not explored.

○ Symmetry simplification: Definition of the symmetry metric as an area comparison between actual and maximum using the available perimeter.

- Validate:

- Last time slice only: The validation is based on the symmetry of the last time slice shape versus considering the symmetry of the aging uncertainty point cloud itself.

- Simulation simplification: The simulation considers neither the speed of impact diffusion nor the influence of causal loops. 
- No comparison of forecast accuracies: The framework was not applied for (comparative) forecasting efforts in order to determine estimation accuracy and factors influencing such.

\section{Conclusions and recommendation for future work}

The problem addressed by the investigation is the quantification of cost uncertainty under conditions of small data. Based upon an analysis of the context data using principles of spatial geometry analysis a relevant framework, although with numerous limitations, was developed. Application of the framework demonstrates that, for the data context, with increasing symmetry over time the cost variance (uncertainty) for the data context also increases over time. Symmetry therefore illustrates similar properties to cost variance (uncertainty) and is suggested as a viable alternative for the quantification of cost uncertainty through arithmetic perspectives. The dependency model suggests an explanation for this correlation.

Specific conclusions drawn from the case study experiments suggest that cost variance can be quantified through spatial geometry metrics, the propagation of spatial geometries can be described through the concept of symmetry and a relationship appears to exist between the symmetry of cost variance data at time $=0$ and the cost variance value at time $=1$, which might be propagated accurately over the desired forecast length. The reasons for the relationship between current symmetry and future cost variance remain unclear but are attributed to the ability of the dependency model to describe the variance behaviour of the relevant context from a systems perspective.

The framework can hence be used to:

- Determine the "headwind" of cost variance; therefore how this variance will change if no intended interventions occur.

- Optimise financial contingency setting and its release patterns.

- Populate the "most likely" value of a Monte Carlo simulation.

- Describe how cost estimate uncertainty will change over time versus simply setting a single point figure that is intended to be valid across the complete whole product life cycle. 
- Identify the signs for future cost variance through a dependency model.

In this manner the framework will support especially the needs of leaders to adjust decision making criteria for (no-) proceed decisions under conditions of small data [45, 46, 47]. In comparison to existing techniques the proposed method may also lead to more robust estimation approaches that allow for more accurate planning and lower costs due to the improved setting of financial contingencies including release patterns for such.

Additionally the framework encourages the spread of state-of-the-art cost estimation techniques by supporting the rigid separation of technical baseline cost estimation, the management of cost variance through risk management methods and the clear boundary setting to uncertainty as unintended future events with $100 \%$ probability and unknown impact. As illustrated in Figure 30 the rise in cost variance over time due to uncertainty can be forecast and considered in budgetary decision making or when determining optimal points in time to refresh baselines and risk contingency.

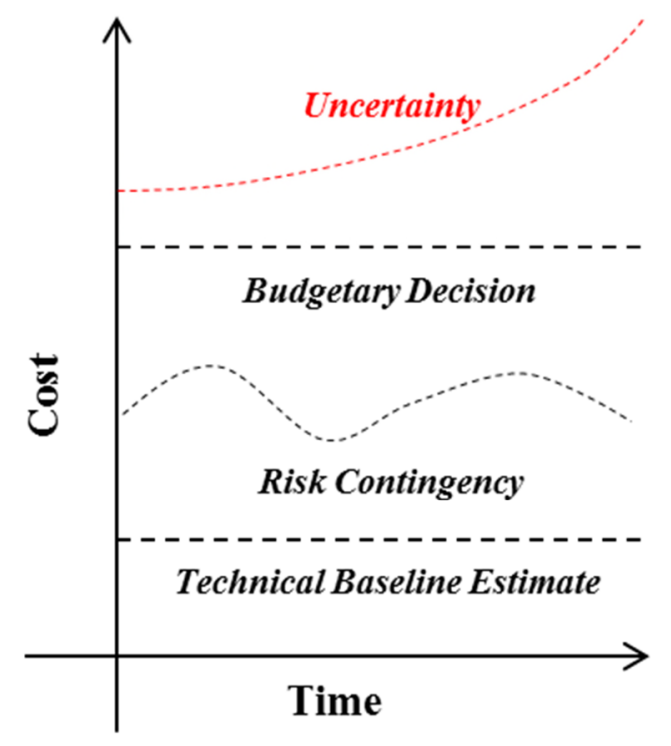

Figure 30: Future state estimation model

Future work is recommended to reduce the framework limitations, especially by: 
- generalisating the method by applying it to other contexts (i.e. the United Kingdom National Audit Office Major Project Reports [48] with the cost variance dimensions: Changed capital requirements, Technical factors, Budgetary factors, Accounting adjustments and redefinitions, Receipts, Procurement processes, Procurement processes internal collaboration, Exchange rate, and Inflation) and

- the impact of using the framework on cost estimation practice if it is used to determine the most likely value for Monte Carlo simulations.

\section{Acknowledgements}

The authors wish to thank all interviewees listed in Table 13 for their continued feedback and support. The authors also wish to thank the anonymous referees for their feedback and comments which have led to a significant improvement in the paper. 


\section{Key term and definitions}

\section{Key terms used in this paper and their definitions are listed in Table 15Error!}

\section{Reference source not found..}

Table 14. Key terms and definitions

\begin{tabular}{lc}
\hline Term & Definition \\
\hline
\end{tabular}

Area

Cost diffusion

Cost dimensions

Cost risk

Cost variance propagation

Cost uncertainty

Cost variance

Deep uncertainty

Financial baseline

Forecast

Innovative

Perimeter

Polytope

Probability space

Reference shape

Response surface

Small / scarce data

Spatial geometry
That surface within the perimeter of a polytopal reference geometry created by visualising the cost variance as vertex values at a specific point in time.

The propagation of cost variance over time.

The cost variance types reported on, i.e. quantity, schedule, engineering, estimating, other, and support.

Potential unintended future cost variance with a probability of $<100 \%$ and an estimated quantity.

The pattern describing the change in cost variance over time.

Manifested and unintended future cost variance with a probability of $100 \%$ and an unknown quantity. This is measured as changes in the compounded cost variance over time.

The absolute difference between the financial baseline and reported cost at any point in time.

A decision-making situation where Knightian uncertainty, conflicting divergent paradigms and emergent decision making are relevant.

The fiscal value of the initial cost dimensions used for planning purposes.

The time period between the time of estimation and the time estimated for.

An attribute of products or services where no (repeatable) verified cost model exist.

The absolute length of the edges of the polytopal reference geometry created by visualising the cost variance dimensions at a specific point in time. This represents the boundary of the point cloud created by cost variance data.

A geometric object with flat sides.

That space within which cost variance data exists as a point cloud.

The polytopal geometry used for the evaluation of symmetry.

The surface of a wrapper applied to a point cloud in order to convert it into a geometric shape.

Data sets which are significantly smaller than those encountered in daily practice and arise from a context of few measurement points, little prior experience, little to no known history, low quality data and conditions of deep uncertainty.

The description of data populations using polytopes. 
Symmetry

Topology
The ratio between the actual area and the maximum area as determined by the base of the reference shape.

The polytopal geometry created by the n-dimensional surface of a point cloud.

\section{References}

[1] Knight, F.H. (1921) “Risk, Uncertainty and Profit”, Houghton Mifflin Company, New York (republished in 2006 by Dover Publications, Inc., Mineola, N.Y.), Retrieved August $4^{\text {th }}, 2015$ from https://mises.org/library/risk-uncertainty-and-profit

[2] Boy, N. (2009) “Calculating Risk and Uncertainty”, Paper for King's College Risk Research Symposium, Retrieved August $4^{\text {th }}, 2015$ from

http://www.google.co.uk/url?sa=t\&rct=j\&q=\&esrc=s\&frm=1\&source=web\&cd=1\&cad=rja\&uact=8\&ve d=0CCMQFjAAahUKEwj2rb-

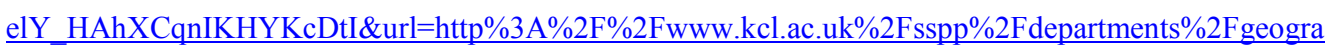
phy $\% 2$ Fresearch $\% 2$ Fhrg\% $\%$ Fresearchsymposium $\% 2$ F2aBoy.pdf\&ei=wozAVfbEEsLVygOCubqQDQ\&u $\underline{\mathrm{sg}=\mathrm{AFQjCNGc77Te} 3 \mathrm{NXkSPT7} \text { w0Q9B3idBOb 1A\&bvm=bv.99261572,d.bGQ }}$

[3] Wierman, M.J. (2010) "An Introduction to the Mathematics of Uncertainty", Center for the Mathematics of Uncertainty, Creighton University, Retrieved August $19^{\text {th }}, 2015$ from http://www.google.co.uk/url?sa=t\&rct=j\&q=\&esrc=s\&frm=1\&source=web\&cd=1\&cad=rja\&uact=8\&ve $\underline{\mathrm{d}=0 \mathrm{CCYQFjAAahUKEwiN0}-}$ fwrXHAhUBHBQKHRz2AD0\&url=http $\% 3 \mathrm{~A} \% 2 \mathrm{~F} \% 2 \mathrm{Fwww}$.creighton.edu $\% 2 \mathrm{Ffileadmin} \% 2 \mathrm{Fuser} \% 2 \mathrm{~F}$ CCAS\%2Fprograms\%2Ffuzzy math\%2Fdocs\%2FMOU.pdf\&ei=wajUVc3uA4G4UJzsggD\&usg=AFQjCNFoNA8rb8G0uRn8Q7Rc-Xz4Hxyqzg\&bvm=bv.99804247,d.d24

[4] Aven, T. (2013) “On How to Deal with Deep Uncertainties in a Risk Assessment and Management Context”, Risk Analysis, Vol. 33, Issue 12, pp. 2082-2091, Retrieved August $4^{\text {th }}, 2015$ from http://onlinelibrary.wiley.com/doi/10.1111/risa.12067/pdf

[5] Caron, F. (2013) "Managing the Continuum: Certainty, Uncertainty, Unpredictability in Large Engineering Projects”, Springer Briefs in Applied Sciences, ISBN 978-88-470-5244-4

[6] United States Department of Defense (2006) "Risk Management Guide for DoD Acquisition”, 6th ed., Accession Number ADA470492, Retrieved August 4 ${ }^{\text {th }}, 2015$ from http://www.dtic.mil/cgi-

bin/GetTRDoc?Location $=\mathrm{U} 2 \& d o c=$ GetTRDoc.pdf\&AD $=$ ADA470492

[7] United States Government Accountability Office (2009) "Cost Estimating and Assessment Guide, Best Practices for Developing and Managing Capital Program Costs", GAO-09-3SP, Retrieved August $4^{\text {th }}, 2015$ from http://www.gao.gov/products/GAO-09-3SP

[8] North Atlantic Treaty Organisation (2009) "Code of practice for life cycle costing", RTO Publication, SAS-069, Retrieved August 19 ${ }^{\text {th }}, 2015$ from https://www.cso.nato.int/Pubs/rdp.asp?RDP=RTO-TR-SAS$\underline{069}$ 
[9] Smit, M.C. (2012) “A North Atlantic Treaty Organisation framework for life cycle costing”, International Journal of Computer Integrated Manufacturing, Vol. 25, pp. 444-456, Retrieved August $19^{\text {th }}$, 2015 from http://www.tandfonline.com/doi/abs/10.1080/0951192X.2011.562541?journalCode=tcim20

[10] United States Naval Center for Cost Analysis (2014) “Joint Agency Cost Schedule Risk and Uncertainty Hand Book", Retrieved August 4 ${ }^{\text {th }}, 2015$ from https://www.ncca.navy.mil/tools/csruh/index.cfm

[11] Ghanmi, A., Rempel, M., Sokri, A., Solomon, B. (2014) “Cost Risk Framework”, Defence Research and Development Canada, Scientific Report, DRDC-RDDC-2014-R167, Retrieved August 19 ${ }^{\text {th }}, 2015$ from http://pubs.drdc-rddc.gc.ca/BASIS/pcandid/www/engpub/DDW?W\%3DSYSNUM=800951

[12] White, B. E. (2009) “Complex Adaptive Systems Engineering (CASE)”, Systems Conference, 2009 3rd Annual IEEE, Vancouver, BC, pp. 70-75, DOI: 10.1109/SYSTEMS.2009.4815774, Retrieved August $4^{\text {th }}, 2015$ from

http://ieeexplore.iee. $\mathrm{org} / \mathrm{xpl} / \operatorname{login} . j \mathrm{sp} ? \mathrm{tp}=\&$ arnumber=4815774\&url=http $\% 3 \mathrm{~A} \% 2 \mathrm{~F} \% 2$ Fieeexplore.iee. rg\%2Fxpls\%2Fabs_all.jsp\%3Farnumber\%3D4815774

[13] Haskins, C. ed. (2010) "INCOSE Systems Engineering Handbook v. 3.2”, International Council on Systems Engineering, INCOSE-TP-2003-002-03.2, Retrieved August $4^{\text {th }}, 2015$ from https://www.google.co.uk/url?sa=t\&rct=j\&q=\&esrc=s\&frm=1\&source=web\&cd=20\&ved=0CGQQFjAJ OApqFQoTCJSAmeuPj8cCFUTDcgod4hgPBg\&url=https $\% 3 \mathrm{~A} \% 2 \mathrm{~F} \% 2$ Fteoriaorganizacional.files.wordp ress.com\%2F2014\%2F05\%2Fse-handbook-2010-0201-v3-2-updated-final-85x11.pdf\&ei=GIfAVZSUIcSGywPisbww\&usg=AFQjCNFyhdppX6TEAsIWqudQo9jXQFLzOQ\&bvm= bv.99261572,d.bGQ

[14] Erkoyuncu, J.A., Durugbo, C., Shehab, E., Roy, R., Parker, R., Gath, A., Howell, D. (2013) "Uncertainty driven service cost estimation for decision support at the bidding stage", International Journal of Production Research, Vol. 51, Issue 19, pp. 5771-5788, Retrieved August $4^{\text {th }}, 2015$ from http://www.tandfonline.com/doi/abs/10.1080/00207543.2013.794318

[15] Hamarat, C., Kwakkel, J.H., Pruyt, E. (2013) “Adaptive Robust Design under deep uncertainty”, Technological Forecasting and Social Change, Vol. 80, Issue 3, pp. 408-418, Retrieved August $4^{\text {th }}, 2015$ from http://www.sciencedirect.com/science/article/pii/S004016251200248X

[16] Schwabe, O., Shehab, E., Erkoyuncu, J.A. (2015) "Uncertainty Quantification Metrics for Whole Product Life Cycle Cost Estimates in Aerospace Innovation”, Journal Progress in Aerospace Sciences, pp. 1-24, DOI: 10.1016/j.paerosci.2015.06.002, Retrieved August $4^{\text {th }}, 2015$ from http://www.sciencedirect.com/science/article/pii/S0376042115000433

[17] Mlodinow, L. (2002) "Euclid's Window: The Story of Geometry from Parallel Lines to Hyperspace", Penguin Books, London, England, ISBN-10: 0684865246

[18] Ghrist, R. (2008) "Barcodes: The Persistent Topology of Data", Bulletin (New Series) of the American Mathematical Society, Vol. 45, pp. 61-75, Retrieved August 4 ${ }^{\text {th }}, 2015$ from http://www.ams.org/journals/bull/2008-45-01/S0273-0979-07-01191-3/

[19] Mitra, N.J., Pauly, M., Wand, M., Ceylan, D. (2012) "Symmetry in 3D Geometry: Extraction and Applications", Eurographics, State of the Art Report, Retrieved August 4 ${ }^{\text {th }}, 2015$ from 


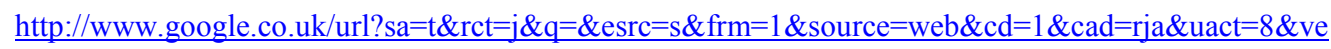

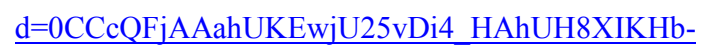

CC8s\&url=http\%3A\%2F\%2Fwww0.cs.ucl.ac.uk\%2Fstaff\%2Fn.mitra\%2Fresearch\%2Fsymmetry survey \%2Fpaper_docs\%2FsymmetryStar_small_EG12.pdf\&ei=koLAVdTKOofiywO ha7YDA\&usg=AFQjCN GoAKgdgHjXcz0zztkYvHdxZKOwjQ\&bvm=bv.99261572,d.bGQ

[20] Robbin, T. (2015) “Topology and the Visualization of Space”, Symmetry, Vol. 7, pp. 32-39, Retrieved August $4^{\text {th }}, 2015$ from http://www.mdpi.com/2073-8994/7/1/32

[21] Porter, T. (2004) "Karl Pearson: the scientific life in a statistical age", Princeton, Princeton University Press, ISBN-10: 0691126356

[22] Hilbert, D., Nordheim, L., von Neumann, J. (1927) “Über die Grundlagen der Quantenmechanik”, Mathematische Annalen, Issue 98, pp. 1-30, Retrieved August $4^{\text {th }}, 2015$ from http://rd.springer.com/article/10.1007\%2FBF01451579\#

[23] Berberian, S.K. (1961) "Introduction to Hilbert Space”, American Mathematical Society, AMS Chelsea Publishing, ISBN-10: 0821819127, Retrieved August $4^{\text {th }}, 2015$ from https://archive.org/details/IntroductionToHilbertSpace

[24] Uffink, J.B.M. (1990) “Measures of Uncertainty and the Uncertainty Principle”, PhD diss., Reference Number 23012820, Rijksuniversiteit Utrecht, Netherlands, Retrieved August $4^{\text {th }}, 2015$ from

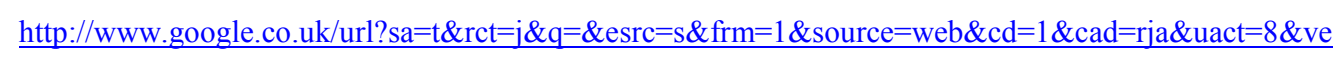
$\mathrm{d}=0 \mathrm{CCcQFjAAahUKEwiPhJqVg} 4$ HAhWG_XIKHTC6Dlo\&url=http\%3A\%2F\%2Fwww.phys.uu.nl\%2 Figg\%2Fjos\%2Fpublications\%2Fproefschrift.pdf\&ei=znnAVY 1O4b7ywOw9LrQBQ\&usg=AFQjCNGe fb10whL355H9F1e4uvjx QUvpg\&bvm=bv.99261572,d.bGQ

[25] Augusdinata, B. (2008) "Exploratory modeling and analysis. A promising method to deal with deep uncertainty", PhD diss., Technische University of Delft, Netherlands, Retrieved August $4^{\text {th }}, 2015$ from http://repository.tudelft.nl/view/ir/uuid\%3A8a371ab4-3582-4506-bbd2-685e127f8bd7/

[26] Schwabe, O., Shehab, E., Erkojuncu, J. (2015) “Geometric Quantification of Cost Uncertainty Propagation: A Case Study”, Procedia CIRP, Vol. 37, 2015, pp.158-163, CIRPe 2015 - Understanding the life cycle implications of manufacturing, Retrieved October 13th, 2015 from http://www.sciencedirect.com/science/article/pii/S2212827115009324

[27] Kenny, S.P., Crespo, L.G., Giesy, D.P. (2012) "Variation uncertainty quantification toolbox, introduction and tutorial”, Series NASA/TM 2012-217561, Retrieved October 11 ${ }^{\text {th }}, 2015$ from http://purl.fdlp.gov/GPO/gpo28754

[28] Carlsson, G. (2009) “Topology and data”, Bulletin (New Series) of the American Mathematical Society, Vol. 46, pp. 255-308, Retrieved August $4^{\text {th }}, 2015$ from http://www.ams.org/journals/bull/200946-02/S0273-0979-09-01249-X/

[29] Thims, L. (2012) “Thermodynamics $\neq$ Information Theory: Science's Greatest Sokal Affair”, Journal of Human Thermodynamics, Vol. 8, Issue 1, pp. 1-120, Retrieved September $12^{\text {th }}, 2015$ from http://www.google.co.uk/url?sa=t\&rct=i\&q=\&esrc=s\&frm=1\&source=web\&cd=1\&cad=rja\&uact=8\&ve 
d=0CCEQFjAAahUKEwj7vcv7mPHHAhXMbxQKHTAvBcY\&url=http\%3A\%2F\%2Fwww.humanther modynamics.com\%2FTNETIT.pdf\&usg=AFQjCNGKCxOLrRI25KN46_I3oHUdoKqhIQ

[30] Bubenik, P., Carlsson, G., Kim, P. (2009) "Data Analysis using Computational Topology and Geometric Statistics”, Banff International Research Station (BIRS), Research workshop, March 8-13, 2009, Retrieved August $4^{\text {th }}, 2015$ from

https://www.google.co.uk/url?sa=t\&rct=i\&q=\&esrc=s\& frm=1\&source=web\&cd=1\&ved=0CCMQFjAAa hUKEwimlKLNII HAhWmD3IKHfc1Bus\&url=https\%3A\%2F\%2Fwww.birs.ca\%2Fworkshops $\% 2$ F200 9\%2F09w5112\%2Freport09w5112.pdf\&ei=F4zAVeasOqafyAP365jYDg\&usg=AFQjCNH19LINcPRmtr PP54vrJFQavZd31Q\&bvm=bv.99261572,d.bGQ

[31] Bubenik, P., Kim, P.T. (2007) “A statistical approach to persistent homology”, Homology Homotopy and Applications, Vol. 9, pp. 337-362, Retrieved August $4^{\text {th }}, 2015$ from

http://scholar.google.co.uk/scholar url?url=http://projecteuclid.org/download/pdf 1/euclid.hha/12011273

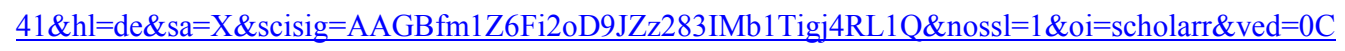
CEQgAMoADAAahUKEwiBiaCtII HAhXIwHIKHQF5BEQ

[32] Edelsbrunner, H., Letscher, D., Zomorodian, A. (2001) “Topological persistence and simplification”, Discrete and Computational Geometry, Vol. 28, pp. 511-533, Retrieved August $4^{\text {th }}, 2015$ from http://rd.springer.com/article/10.1007\%2Fs00454-002-2885-2\#

[33] Smith, A., Shu-Ping, H. (2005) “Common Errors When Using Risk Simulation Tools”, Tecolote Research, SCEA/ISPA Denver CO, Retrieved August 4 ${ }^{\text {th }}, 2015$ from https://www.aceit.com/docs/default$\underline{\text { source/conference-papers/ICEAA/common-errors-when-using-risk-simulation-tools.zip?sfvrsn=2 }}$

[34] Black, H.M. (2008) “U.S. Aerospace Industry Cost Risk Analysis Survey”, National Estimator, pp. 14-17, Retrieved August $4^{\text {th }}, 2015$ from http://www.google.co.uk/url? sa=t\&rct=j\&q=\&esrc=s\&frm=1\&source=web\&cd=1\&cad=rja\&uact=8\&ve d=0CCMQFjAAahUKEwiJnJq01o HAhWCKnIKHd19BBo\&url=http $\% 3 \mathrm{~A} \% 2 \mathrm{~F} \% 2 \mathrm{Fwww}$.iceaaonline.co m\%2Fready\%2Fwp-content $\% 2$ Fuploads $\% 2$ F2014\%2F03\%2F2008-National-Estimator-

Fall.pdf\&ei= I3AVYmuEILVyAPd-

$\underline{\text { 5HQAQ\&usg=AFQjCNH DVcuXyLnqXdLzsAz0emgMWCbSQ\&bvm=bv.99261572,d.bGQ }}$

[35] Niazi, A., Dai, J., Balabani, S., Seneviratne, L. (2006) "Product Cost Estimation: Technique

Classification and Methodology Review", Journal of Manufacturing Science and Engineering, May 2006, Vol. 128, Retrieved August 19 ${ }^{\text {th }}, 2015$ from

http://manufacturingscience.asmedigitalcollection.asme.org/article.aspx?articleid=1450629

[36] Goh, Y. M., Newnes, L. B., Mileham, A. R., McMahon, C. A., Saravi, M. E. (2010) "Uncertainty in Through-Life Costing - Review and Perspectives", IEEE Transactions on Engineering Management, Vol. 57, No. 4, Retrieved August $19^{\text {th }}, 2015$ from

http://ieeexplore.ieee.org/xpl/articleDetails.jsp?arnumber $=5432980$

[37] Hamaker, J. W. (2011) "What are Quality Cost Estimates? or the $260 \mathrm{~Hz}$ Cost Estimate", Journal of Parametrics, Vol. 26, Issue 1, pp. 1-7, Retrieved September 1 ${ }^{\text {st }}, 2015$ from $\underline{\text { http://www.tandfonline.com/doi/abs/10.1080/10157891.2007.10462275 }}$ 
[38] Wheeler, D.J. (2012) "Myths about data analysis", 2012 International Lean and Six Sigma

Conference, Orlando, Florida, USA, Retrieved August $4^{\text {th }}, 2015$ from

www.spcpress.com/pdf/DJW238.pdf

[39] Xu, Y., Elgh, F., Erkoyuncu, J. A., Bankole, O., Arundachawat, P., Goh, M. Y, Cheung, W. M., Wahid, B. M., Wang, Q., Baguley, P., Newness L., Shehab, E., Roy, R. (2012) “Current and Future Research in Cost Engineering", International Journal of Computer Integrated Manufacturing, Vol. 25, Issue 4-5, Retrieved August 19 ${ }^{\text {th }}, 2015$ from http://www.tandfonline.com/doi/full/10.1080/0951192X.2010.542183\#abstract

[40] Smart, C. (2014) "Bayesian Parametrics: How to Develop a CER with Limited Data and Even Without Data", International Cost Estimating and Analysis Association, Retrieved September $1^{\text {st }}, 2015$ from http://www.iceaaonline.com/2014-iceaa-professional-development-training-workshop/2014-bestpapers/

[41] United States Department of Defence (2015) "Selected Acquisition Reports (SAR) Summary Tables", Retrieved July $24^{\text {th }}, 2015$ from http://www.acq.osd.mil/ara/am/sar/

[42] Breaux, B.F., Lee, R.C., Braxton, P.J., Cincotta, K.M., Flynn, B.J. (2012) "SAR Data Analysis, CV Benchmarks, and the Updated NCCA S-Curve Tool", ISPA/SCEA Conference (Brussels, Belgium) and SCEA/ISPA Conference (Orlando, Florida, USA), Retrieved August $4^{\text {th }}, 2015$ from http://www.google.co.uk/url?sa=t\&rct=j\&q=\&esrc=s\&frm=1\&source=web\&cd=2\&cad=rja\&uact=8\&ve $\mathrm{d}=0 \mathrm{CCoQFjABahUKEwjewqXk1I+HAhVjdXIKHdRWBTg \& url=http} \% 3 \mathrm{~A} \% 2 \mathrm{~F} \% 2 \mathrm{Fwww}$.technomics.net \%2Ffiles $\% 2$ Fdownloads $\% 2$ Fscea $\% 2$ F2012\%2FSCEA-SAR-Data-NCCA-S-Curve-

Tool_w\%2520Backup\%2520slides.pdf\&ei=SIzAVd7-

DuPqyQPUrZXAAw\&usg=AFQjCNF5MjIeDJnXVvjVn2lagKwZhHIHbw\&bvm=bv.99261572,d.bGQ

[43] Forrester, J.W. (1958) “Industrial dynamics - a major breakthrough for decision makers", Harvard Business Review Vol. 36, Issue 4, pp. 37-66, Retrieved August 19 ${ }^{\text {th }}, 2015$ from http://www.google.co.uk/url?sa=t\&rct=j\&q=\&esrc=s\&frm=1\&source=web\&cd=1\&cad=rja\&uact=8\&ve $\mathrm{d}=0$ CCQQFjAAahUKEwi04OOxurXHAhVGVBQKHWGoB9I\&url=http\%3A\%2F\%2Fwww.lottepiil.dk \%2Fkandidat \%2FIndustrial\%2520Dynamics\%2520(Forrester\%25201958).pdf\&ei= J UVbTyN8aoUeH QnpAN\&usg=AFQjCNG4rGR3G2EQGBttrbMN3Sb0LY7MiA

[44] Sterman, J.D. (2000) "Business Dynamics: Systems Thinking and Modelling for a Complex World", McGraw-Hill Higher Education, ISBN-10: 0071179895

[45] Lempert, R.J., Groves, D.G., Popper, S.W., Bankes, S.C. (2006) “A General, Analytic Method for Generating Robust Strategies and Narrative Scenarios”, Management Science, Vol. 52, No. 4, pp. 514528, Retrieved August $4^{\text {th }}, 2015$ from http://pubsonline.informs.org/doi/abs/10.1287/mnsc.1050.0472? journalCode=mnsc

[46] Mahnovski, S, (2007) "Robust Decisions and Deep Uncertainty”, PhD diss., Pardee RAND Graduate School, Retrieved August $4^{\text {th }}, 2015$ from http://www.rand.org/pubs/rgs dissertations/RGSD210.html?src=mobile

[47] Snowden, D.J., Boone, M.E. (2007) “A Leaders Framework for Decision Making”, Harvard Business Review, Vol. 85, Issue 11, pp. 69-76, Retrieved August $4^{\text {th }}, 2015$ from https://hbr.org/2007/11/a-leaders-framework-for-decision-making 
[48] United Kingdom National Audit Office (2014) "Major Projects Report 2014 and the Equipment Plan 2014 to 2024", Retrieved July $24^{\text {th }}, 2015$ from http://www.nao.org.uk/report/major-projects-report-2014and-the-equipment-plan-2014-to-2024/\# 


\section{A framework for geometric quantification and forecasting of cost uncertainty for aerospace innovations}

Schwabe, Oliver

Elsevier

Oliver Schwabe, Essam Shehab, John Erkoyuncu, A framework for geometric quantification and forecasting of cost uncertainty for aerospace innovations, Progress in Aerospace Sciences, Volume 84, July 2016, pp29-47

http://dx.doi.org/10.1016/j.paerosci.2016.05.001

Downloaded from Cranfield Library Services E-Repository 